Portland State University

PDXScholar

5-1991

\title{
Identity formation : a comparison of adolescents adopted through agency versus private placements
}

Judith Kay Bentley

Portland State University

Follow this and additional works at: https://pdxscholar.library.pdx.edu/open_access_etds

Part of the Psychology Commons

Let us know how access to this document benefits you.

\section{Recommended Citation}

Bentley, Judith Kay, "Identity formation : a comparison of adolescents adopted through agency versus private placements" (1991). Dissertations and Theses. Paper 4115.

https://doi.org/10.15760/etd.5999

This Thesis is brought to you for free and open access. It has been accepted for inclusion in Dissertations and Theses by an authorized administrator of PDXScholar. Please contact us if we can make this document more accessible: pdxscholar@pdx.edu. 
AN ABSTRACT OF THE THESIS OF Judith Kay Bentley for the Master of Arts in Education, Counselor Education Program presented May 6, 1991.

Title: Identity Formation: A Comparison of Adolescents Adopted through Agency versus Private Placements.

APPROVED BY THE MEMBERS OF THE THESIS COMMITTEE:
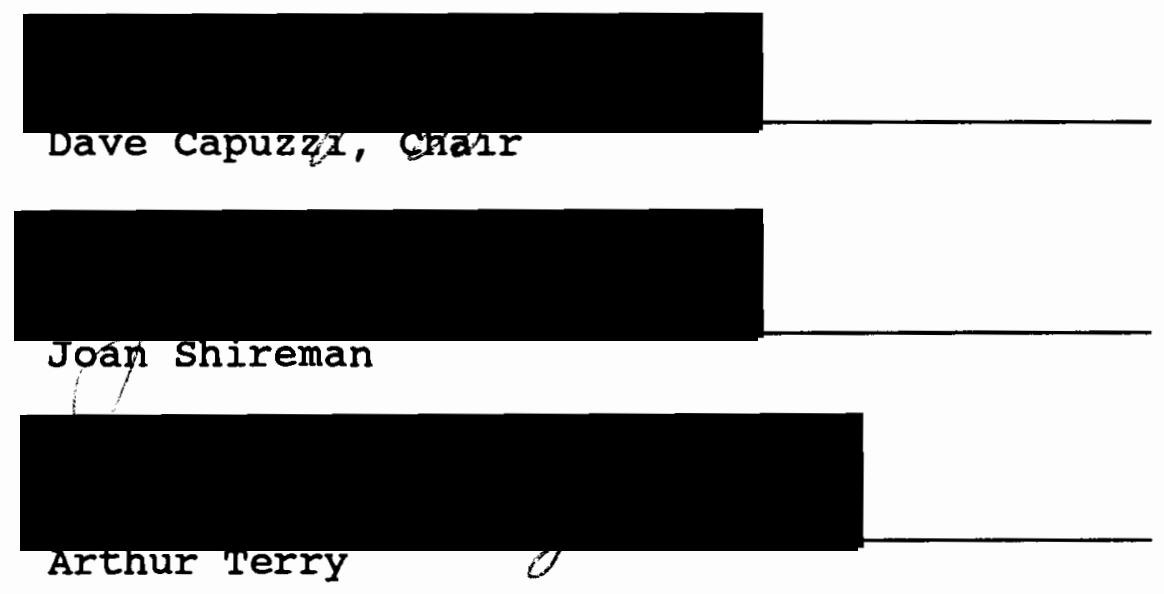

The purpose of this study was to investigate factors which might influence the identity formation process in adopted adolescents. Specifically, this research looked at agency versus independent adoption placement as a choice reflecting the adoptive parents' preference for involvement 
with or distance from a possible adoptive family support network before and after placement. Subjects were also divided according to those whose family had belonged to an adoptive family support group and those who had not. The study involves a combination of descriptive and correlational research methods.

Subjects were eighteen adolescent volunteers from 14 to 18 years of age who had been adopted as infants. The subjects from this study were also compared with 50 adopted and 41 nonadopted adolescents in the Delaware Family study (DFS). A modified Social Atom, a Semi-structured Interview (designed for the DFS) and the offer self-Image Questionnaire (OSIQ) were administered to all subjects. The sample in this study had significantly lower scores on the OSIQ than the adopted and the nonadopted samples in the DFS. Possible explanations for some adopted adolescents having more difficulty with identity formation than others were the focus of the study.

Statistical analyses of score differences between the two sets of subjects (Agency vs. Independent; support Group vs. No Support Group), revealed very limited statistically significant results. It appears that support group involvement may be beneficial, but the sample is too small generalize the results. The effect of Same Race vs. Transracial adoption was also analyzed, again showing very limited difference between the two groups. In this sample 
of 10 adolescents adopted by parents of the same race and 8 adopted transracially, the only area of significant difference was the sexual self score on the osIQ.

Family factors investigated indicated that adolescents need parents who are influential in their lives and that, in some cases, adoptive status and its ramifications may negatively affect family relationships. 
IDENTITY FORMATION: A COMPARISON OF ADOLESCENTS

ADOPTED THROUGH AGENCY VERSUS PRIVATE PLACEMENTS

by

JUDITH KAY BENTLEY

A thesis submitted in partial fulfillment of the requirements for the degree of

MASTER OF ARTS

in

EDUCATION

Portland state University

1991 
TO THE OFFICE OF GRADUATE STUDIES:

The members of the committee approve the thesis of Judith Kay Bentley presented May 6, $19,91$.
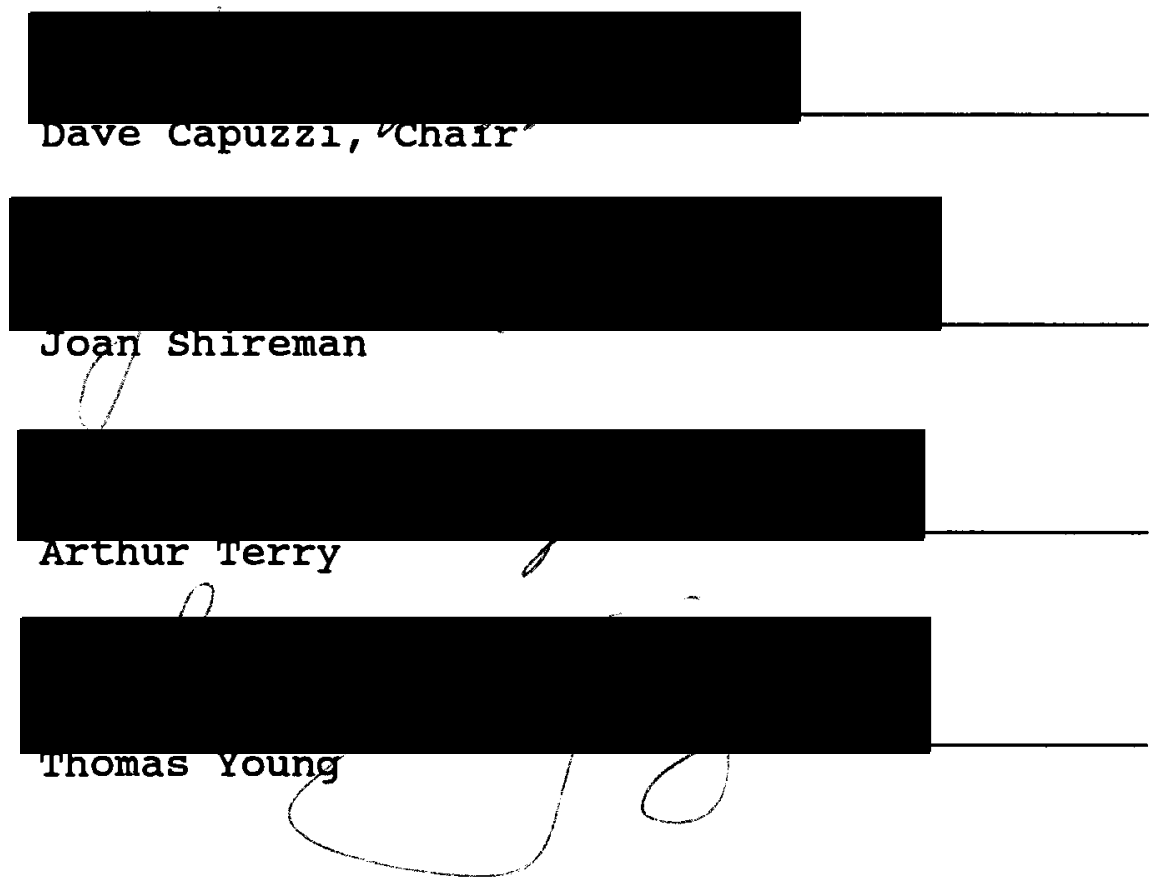

APPROVED :

Robert Everhart, Dean, school of Education

c. WIIILan savery, Interint vicevfrovost

for Graduate studies and Research 


\section{ACKNOWLEDGMENTS}

I wish to express my appreciation to...

...Plan International Adoption Service, with special recognition of the efforts of Ann Scott, Julie Eagleson and Delores Lauber;

...Dr. Janet Hoopes, of the Delaware Family Study, for her cooperation and assistance;

...the school counselors who helped locate adopted adolescents in their student populations, especially Bev Bain and Wade scott;

...my statistics consultant, Robert Schuff;

...my thesis committee who generously volunteered their precious time;

... and, especially, the volunteer who agreed to help me learn more about what it is like to be an adopted adolescent.

The list of those who helped at some stage in the preparation of this thesis is too long to include here, but to all I say a heartfelt "Thank you." 
TABLE OF CONTENTS

PAGE

ACKNOWLEDGMENTS

LIST OF TABLES.

\section{CHAPTER}

I INTRODUCTION. . . . . . . . . . . . . . . . 1

Identity. . . . . . . . . . . . . . 2

Adoption Dynamics . . . . . . . . . . 3

The Problem and Purpose of the Study. . . . . 5

Hypothesis. . . . . . . . . . . . . 9

Definition of Terms. . . . . . . . . . . 9

II REVIEW OF THE LITERATURE . . . . . . . . . . 12

Identity Formation and Adoption . . . . . . 12

Family Dynamics Related to Identity

Formation and Adoption . . . . . . . 17

Adoption Dynamics and Identity. . . . . . 23

III METHOD. . . . . . . . . . . . . . . 29

subjects. . . . . . . . . . . . . 30

Procedure . . . . . . . . . . . 33

Instruments . . . . . . . . . . . . 34

Social Atom

Offer Self-Image Questionnaire

Semi-structured Interview 
Experimental design... . . . . . . . 36

Limitations. . . . . . . . . . . 37

Other Question for Exploration. . . . . . 38

IV RESULTS AND DISCUSSION . . . . . . . . . . 40

Major Findings. . . . . . . . . . . 40

Method of Placement

Support Group Participation

Comparison with the Delaware Family

study

Same Race vs. Transracial Adoption

Family Relationships

Additional Findings . . . . . . . . . . .

Adoption Status

Physical and Personality

Similarity to Parents

Timing of Disclosure

Satisfaction with Information Given

about Their Adoption

V

SUMMARY

Summary of Major Findings . . . . . . . 57

Implications for Practice . . . . . . . 61

Directions for Future Research. . . . . . 62

REFERENCE LIST. . . . . . . . . . . . . . . . . 64

APPENDICES

A SOCIAL ATOM . . . . . . . . . . . . . 68

B SEMI-STRUCTURED INTERVIEW . . . • . . . . . 71

C FREQUENCY DISTRIBUTION. . . . . . . . . . . 90

D INFORMED CONSENTS . . . . . . . . . . . . . . . 94 


\section{LIST OF TABLES}

TABLE

PAGE

I Mean Scores and Standard Deviations on Ego

Identity Measures for All Subjects

$$
(\mathrm{N}=18) \text {. . . . . . . . . . . . . . . }
$$

II Comparison of Scores on the Interview and the OSIQ for Agency and Independent Subjects

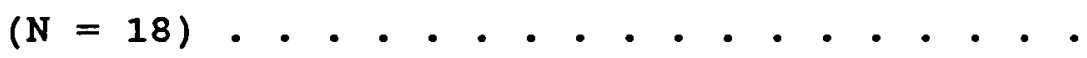

III Comparison of scores on the Interview and the

OSIQ for Support Group and No support

Group Subjects $(\mathrm{N}=18) . . . . . . . . . . .444$

IV Comparison of Adopted Volunteers from Two

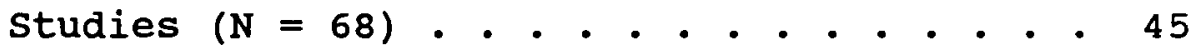

V Comparison of Nonadopted and Adopted Volunteers

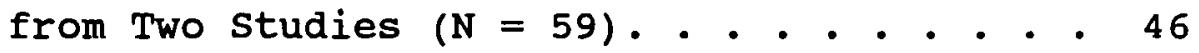

VI Comparison of scores on the Interview and the

OSIQ for Same Race and Transracially

Adopted Subjects $(\mathrm{N}=18)$. . . . . . . . 49

VII Relationship Between Category with Highest

Influence Score (Social Atom) and Overall

Identity $(\mathrm{N}=18) \cdot . \cdot . \cdot . \cdot . \cdot . \cdot . \cdot . \quad 51$ 


\section{CHAPTER I}

\section{INTRODUCTION}

Each person must establish a sense of self during adolescence in order to achieve maturity. According to Erikson, "We may, in fact, speak of the identity crisis as the psychosocial aspect of adolescing" (1968, p. 91). During this time, adolescents begin to wonder what kind of adults they will become. They bring to this process their still-evolving self-esteem and self-concept which they are integrating with their ego identity. It is the formation of a unique individual, seen by the adolescent to be a process with a deadline. Their sense of urgency is heightened by the constant changes in their bodies, thinking processes and emotions. They look outside themselves for models and guidelines as they attempt to negotiate this stage. Lacking the usual genetic reference points, adoptees experience "intensified identity concerns. It is a time when the feelings about adoption become more intense and questions...increase" (Sorosky, Baran \& Pannor, 1975, p. 22).

For the adopted adolescent, the process of identity formation poses unique stresses, yet many adoptees apparently accomplish the task with little or no more 
difficulty than other adolescents. Why, then, do some adopted adolescents find that they cannot form a firm sense of self and answer the question "Who am I?" The purpose of this study is to gather information from adopted adolescents about the impact of adoption on their perceptions of themselves, including the role their families play.

\section{IDENTITY}

In creating the Tan Ego Identity Scale, the authors outlined their own definition of identity, saying it "implies an acceptance of and being comfortable with one's physical self, a sense of direction, and consequently an ability to make decisions" (Tan, Kendis, Fine \& Porac, 1977, p. 279). Others include aspects of self-esteem (being comfortable with one's self-concept).

All of these pieces relate to identity formation in adopted persons. For the child who resembles one or both adoptive parents, identity formation is made easier. However, children often identify differences and enlarge upon them, and often there are significant differences in appearance or personality, or both. In this case, children may find it more difficult to be comfortable with themselves.

Adopted adolescents may solve the problem by internalizing unquestioningly the values, goals, etc. of someone else, such as their parents. This results in an 
identity status called "foreclosure" by James Marcia (1967), which might explain how some adoptees establish an identity without distress.

If the process of forming an ego identity goes awry, the result is identity diffusion which "implies doubts about one's physical and sexual self, an inability to make decisions and commitments because of doubts, and the lack of a sense of continuity of the self over time" (Tan et al, 1977, p. 279). Identity diffusion can be measured as low self-esteem. Feelings of unworthiness or even worthlessness in the adopted person may be partly based on a childhood belief that there had to be something wrong with a child who would be given away by its mother. Or perhaps, the child believes, the birthmother was a bad person, and this "badness" might be inherited. The test instruments used in this study measure self-perceptions as a way of determining each subject's identity status. The areas covered include self-image, self-esteem, family and peer relationships, commitment to moral standards and career/education guidelines, a sense of belonging, and presence or absence of distress in integrating "adoptedness" into the subject's self-image.

\section{ADOPTION DYNAMICS}

"It is an identity dilemma to have two sets of parents, one known and one unknown... This dilemma has to be addressed 
openly throughout life" (Katz, 1980, p. 163). During childhood, addressing this dilemma generally must be done by the child's adoptive parents, although the parents may arrange for others to help, i.e. through activities in an adoptive family support group or special family life units in grade school classrooms. Whether adoptive parents address adoption issues themselves or involve others, they must accept some variations in the way they rear their children compared to rearing biological children. This is a big hurdle for parents who believed they could adopt a child and proceed "just as if she were our own."

Andrews says, "For the majority of adoptees whose parents were nurturing, accepting, and secure enough, a sense of identity does develop from their importance to their parents... The bonds of identification become stronger than the need for biological identity" (1978, p. 317). The conclusion drawn by many sources is that adoptees who have difficulty with identity formation have adoptive parents who were not sufficiently accepting of all facets of their adopted child and not sufficiently secure in their role as adoptive parents. Although genetic, prenatal and neo-natal factors which the adoptee brings to the adoptive family should not be discounted, a major emphasis in recent years has been on the attitudes communicated by the adoptive parents to the adopted child (Small, 1987). 
According to Katz (1980), adoptive families need to accept that

...families who can incorporate all the background facts, negative as well as positive, with

frankness and empathy, have taken a giant step toward preventing: a) a negative self-image in the child based on a lack of information about his history; b) breakdown in family communication because the child's questions are unwelcome and unanswered; c) bitterness and self-hate in the child who conceives his/her antecedents as unacceptable; and d) the child's ultimate disappointment in the adoptive parents because of their unresponsiveness to the need to know about biological origins. (p. 163)

THE PROBLEM AND PURPOSE OF THIS STUDY

Comparing adopted and nonadopted teenagers is usually begun by quoting statistics showing that adopted children form a disproportionately larger percentage of various clinical populations than nonadopted children (Humphrey \& Ounsted, 1963; Offord, Aponte \& Cross, 1969; Schechter, Carlson, Simmons \& Work, 1964; Tec \& Gordon, 1967). Studies have been done with clinical and nonclinical samples of adopted children and adolescents, comparing measures of personality characteristics and social and academic adjustment. Although adopted children usually measure within normal limits in school performance and adjustment, they are also more likely to be rated as having difficulties in these areas (Hoopes, 1990; Shireman, 1988).

Interestingly, the percentage of adopted children who are having difficulties appears to increase as the children 
grow older (Humphrey \& Ounsted, 1963, p. 599). "This, however, may mean only that adoptive parents tend to seek advice more quickly than others, or become more readily concerned about certain aspects of the child's development" (stone, 1972, p. 120). Also contributing to this phenomenon is the fact that heritable behaviors and mental health problems do not always manifest themselves or do not always seem problematical to parents until school age (e.g. hyperactivity) or adolescence (e.g. schizophrenia). It may also mean that as the child matures, the process of integrating more mature concepts about adoption creates increasing stress within the child, and between the child and the adoptive parents.

Family structure is another factor which may affect adolescent adoptees as they work on ego identity. According to Small, "There is a need for empirical research to assess more fully the impact of adoptive family structure upon children of adoption and, most important, to seek the input of (adoptees) as first-person subjects (1987, p. 41). The Delaware Family study (DFS), a longitudinal cohort study, is one of the few attempts to do this with adolescents. It may be that the conclusions of this study--that adopted adolescents do not have greater or more sustained difficulty with tasks of identity formation than nonadopted adolescents--are biased by the nature of the sample. All of the adopted subjects were part of the original population of 
families in a longitudinal study begun in 1962, and had been placed by the same agency.

Since these families were in regular contact with the researchers, it seems likely that they would have been less likely to develop the denial strategies of the "family secret" type used by alcoholic families. When related to adoption the family secret is intended "to minimize the fact that the child was not born to the parents. In this situation, the child's basic sense of self develops around a faulty belief system" leading to a sense of shame or low self-esteem (Small, 1987, p. 36).

When the families in the DFS needed guidance in dealing with adoption issues, they had a built-in support system. Pannor and Nerlove (1977) and Digiulio (1979) have shown that being part of a support group improves the adoptive parents' feelings of comfort in discussing adoption issues with their child and their ability to empathize with the adoptee's need to know about the birth parents.

Families who adopt independently, rather than through an agency, are less likely to have an adoption support system and may be more likely to establish a pattern of denial. Factors which initially influenced the parents to adopted independently may also influence their approach to parenting. These include a strong desire to be in control of whatever situation they are in and relatively impermeable family system boundaries. 
The families in the DFS have not always used agency contacts as a support network, but being part of the study would have provided validation and legitimacy for family building through adoption. Kirk has argued that this is essential to "competent role performance" by adoptive parents (Kirk, 1984). It may also be essential to the role performance of adopted adolescents, which includes identity achievement. Validation of one's role as an adopted person or as an adoptive parent seldom comes from the community, creating discrepancies between their reality and the "cultural script" for parents and children. "situational discrepancies have interpersonal concomitants. We observe four types of role handicap... which interfere with role clarity, with role autonomy, with role obligations, and with sanctions and rewards" (Kirk, 1984, p. 14). The problem for adoptive parents and adoptees is magnified if they are unable to acknowledge their "differentness" and therefore do not look for a reference group that provides validation. The purpose of this study, like the DFS, is to gather information from adopted adolescents about the impact of adoption on their perceptions of themselves, including the role their families play. However, it is assumed that the DFS sample is not representative of all adopted adolescents and that some factors within their family may help to account for the relatively poorer adjustment of other samples of adoptees. Specifically, through measures of 
self-image and ego identity, it is intended that results of the study will provide useful comparisons of adopted adolescents placed independently with those placed through adoption agencies.

\section{HYPOTHESIS}

It is hypothesized that the adolescents who were placed for adoption by agencies will show a more positive selfimage than adolescents who were adopted independently, as measured by the Social Atom, the semi-structured Interview, and the offer self-Image Questionnaire.

\section{DEFINITION OF TERMS}

Agency Adoption--The process of adopting a child in which the prospective adoptive parents work with a licensed placement agency.

Identity--"Ego identity includes three major components: a sense of unity among one's self-perceptions; a sense of continuity of self-definition over time; and a sense of the mutuality between one's self-perceptions and those held by others" (Ambron, Brodzinsky, \& Gormly, 1986, p. 309) .

Independent Adoption--The process of adopting a child in which the prospective adoptive parents take custody of the child directly from the birthparent(s). This 
usually involves a go-between such as a doctor, pastor, attorney, or extended family member.

Out-of-home living arrangements--For the purposes of this research, out-of-home includes those adolescents in foster care and those who have emancipated before finishing high school, making their own arrangements for a place to live.

Self-Concept--one's beliefs and feelings about who and what one is based on the meanings, interpretations and judgments one makes regarding one's experiences and one's self. Once the initial self-concept is formed, usually by the age of five or six, a person tends to interpret experiences and him/herself in ways consistent with the existing self-concept. (Terry, 1986)

Self-Esteem--"Comprised of those aspects or attitudes which can be classified as evaluations of the self or the degree of satisfaction with the self...Three major factors that influence the rise and fall of self-esteem throughout our life are: 1) respect and approval from others; 2) capability, achievement and success; 3) acceptance of, and acting upon, our own inner nature" (Terry, 1986).

Self-image--The way one perceives and defines oneself, including self-concept, self-esteem and perceptions of the role one is assigned by others. 
Self-system--Separate aspects of the self which can be evaluated individually and as a composite. Offer (1969) identifies five: the psychological self, the social self, the family self, the sexual self, and the coping self.

Support Group--People who meet together over a period of time to share their experiences in dealing with similar problems and to provide each other with encouragement, practical advice, and learning opportunities. 


\section{CHAPTER II}

\section{REVIEW OF THE LITERATURE}

The process of identity formation in adopted adolescents involves unique variables yet is, in many ways, the same as the experience of nonadopted persons. Similarly, adoptive families are like all families, yet different. This chapter will examine some of the basic likenesses and differences as they relate to the current research on identity formation, family dynamics and adoption dynamics.

\section{IDENTITY FORMATION AND ADOPTION}

The theory of identity formation as a necessary psychosocial task of the life stage called adolescence began with Erik Erikson (1968). "Erikson spoke of the meshing of all life stages, with the earlier stages preparing for and leading into the next sequential stages" (Hoopes, 1990, p. 144-145). According to Erikson's theory, each succeeding stage builds on the previous stage(s); effectively working through each stage is therefore necessary if succeeding stages are to be handled successfully. In Erikson's paradigm, there are four stages which precede adolescence. Their basic components are 1. Infancy--trust vs. mistrust, 
2. Early childhood--autonomy vs. shame/doubt, 3. Preschool age--initiative vs. guilt, 4. School age--industry vs. inferiority. In stage 5, Adolescence, the basic task is identity vs. identity diffusion (Conger, 1977).

In recent years, adoption workers and theorists have been especially interested in attachment, which is based on the child's choice in infancy to trust or mistrust parent figures. Attachment is "an affectionate bond between two individuals, in this case a parent and an infant, that endures through space and time and serves to join them emotionally" (Kennell, 1976). "If the first relationship a baby has does not set the stage for trust, then later relationships cannot be based on trust... Unattached children do not grow socially. They have great difficulty learning to build any kind of relationship" (Magid \& McKelvey, 1987, p. 62). However, adoption workers diverge from Erikson's theory in that they believe that, in most cases, a child who does not learn to trust in infancy can do so in later stages (Fahlberg, 1979).

Adolescents who have successfully completed the four preceding life stages in Erikson's paradigm should have achieved a healthy sense of self-esteem (Stein \& Hoopes, 1985; Marcia, 1967), which forms the basis for successfully handling the crisis of identity versus role diffusion, concerned with self-concept and social role. 
James Marcia's work on the subject of identity has been especially useful because he defined ego identity in terms of measurable constructs for research purposes. He viewed identity as "an evolving, dynamic entity involving numerous reorganizations of contents throughout one's life" (Stein \& Hoopes, 1985, p. 6). Marcia assigned young adults to one of four "identity statuses" based on two things: (1) their commitment to a sexual orientation, an ideological stance, and a vocational direction and (2) their experience, or failure to experience, a period of decision-making so intense that it constitutes a crisis. The identity statuses are (1) identity achievement--past the crisis and committed to an identity, (2) moratorium--currently in crisis, identity foreclosure--committed without a crisis, and (4) identity diffusion--uncommitted and not working on it.

Because Marcia provided a framework for researchers to use, there have been many studies in the past twenty years based on his work. Use of his paradigm is possible only in late adolescence or adulthood since the process of commitment should have been completed and lack of identity achievement would be significant. However, the personality traits, attitudes and behaviors which Marcia identified as measures of identity have been used in research with younger adolescents, including the work of Daniel offer and his associates. 
Offer's work has been done with teenagers of junior and senior high school age when ego identity is still emerging. He avoids using the term "identity" in his writings, preferring terms such as "self-conception," "self-perception," and "self-image." This is especially appropriate, since offer and his colleagues rely on self-reporting methods to assess the functioning of adolescents rather than professional observers using a scale that differentiates which subjects have achieved identity and which have not, as previous researchers had usually done. Based on studies made with large numbers of teenagers, offer identified five categories for measuring the adolescent's "self-system." These are the psychological self, the social self, the family self, the sexual self, and the coping self.

According to offer, Ostrov and Howard, "Self-image is an important aspect of the psychological functioning of adolescents. It has been found to correlate significantly with other important aspects of their functioning, such as personality development, interpersonal relationships, family relationships" (1984, p. 59). For offer, the adolescent's self-concept ties these areas of functioning with becoming separate and autonomous individuals, or identity achievement.

In the adolescent identity formation stage of Delaware Family study, stein and Hoopes relied on the theoretical 
work of Erikson, Marcia and offer. They also assumed a link between identity formation and adjustment. "The empirical literature on the subject of adjustment as an overall measure of ego identity suggests a rather positive relationship between the two constructs" which allowed stein and Hoopes to use the offer Self Image Questionnaire in the measurement of identity (1985, p. 11). This approach is continued in this study.

In researching identity, various facets of the subject's personality are measured. Theorists may debate the importance, or even the existence, of the unconscious mind and its influence on identity formation. For researchers the most important aspects of identity are measurable phenomena, e.g. behavior and conscious thoughts. These in turn may be influenced to greater or lesser degrees by the inherent personality of the subject. A major area of research into the personality characteristics of adopted persons is in the area of behavioral genetics. A large number of twin and adoptee studies have shown convincingly that there is a genetic component to personality, intelligence and psychopathology. "Obviously, many of these genetic factors are important determinants of adoptee behavior and explanations of adoptee adjustment must take these into account" (Cadoret, 1990, p. 28).

Temperament, by definition, is a genetic component of personality. Three areas of behavior that fit into this 
category are "Activity--sheer energy output,

Sociability--the tendency to approach others, (and)

Emotionality--the tendency to be aroused" (Willerman, 1979, p. 228). These traits affect the adopted child's behavior as an individual, as an interacting member of the family, and in other areas often considered in researching adolescent identity formation. However, the purpose of the current study is to look at environmental factors specific to adopted adolescents' achievement of identity.

\section{FAMILY DYNAMICS RELATED TO IDENTITY FORMATION AND ADOPTION}

The relationships teenagers have with their parents contribute significantly to their developing sense of self. "One important and necessary step in achieving an integrated identity is the gradual loosening of ties to the family...The difficulty of this step depends in large measure on the nature of the parent-child relationship" (Ambron et al, 1986, p. 313). The DFS findings indicated that, "of all the variables considered, quality of family relationships was most predictive of positive identity and adjustment across all groups" (Stein \& Hoopes, 1985, p. 63) . offer et al present findings of additional support for the importance of family relations. "For both adolescent boys and adolescent girls, it seems as if good family relations serve as an emotional inoculator that can ward off emotional 
stress that comes their way in their years of growing up" (1986, p. 135).

Good family relationships are founded on mutual respect, valuing each member of the family as a separate, unique individual, and communicating those basic beliefs in ways the child can understand and accept. "Parental beliefs may be communicated to the child in a subtle manner... An actual statement... on the part of the parent may never have occurred, but a sum of experiences has made the parent's position evident to the child" (McGillicuddy-De Lisi, 1985, p. 7) .

Although parental values may be communicated indirectly, it is also important to establish good oral communication. Within the family system, this means listening and sharing, not just talking. For adoptive families, "perceived openness of family communication about adoption issues was found to enhance identity formation, though it was not quite as predictive of successful outcome as the overall quality of family relationships" (stein \& Hoopes, 1985 , p. 63).

Adolescents need to feel secure enough in their parents' regard to be able to individuate, perhaps rebelliously, without losing the parents' emotional support. This may pose a dilemma for adopted teens in two ways. One is that they have two sets of parents. It is difficult to individuate from (birth) parents one has no contact with and, 
usually, has never known. A second dilemma has to do with parental insecurity.

Most parents of teenagers experience feelings of incompetence; it goes with the territory. For adoptive parents, however, there are added stressors, dealing with the role handicaps described above (Kirk, 1984). Many people still believe that only through the birth process can they become "real" parents. They do not know what their role as adoptive parents of an adolescent requires of them or how to fulfill their additional obligations. Furthermore, they may dislike, or even fear, the loss of autonomy involved in seeking help.

Jealousy of the birthparents may be a serious, if unacknowledged, problem for adoptive parents. This may arise, for instance, if the adoptive parents are being compared unfavorably with the birthparents, who have been idealized in the adopted child's mind. Infertile adoptive parents may resent the birthparents for being able to have a child they did not even want.

The reasons for resentment toward the birthparents on the part of the adoptive parents are many and varied, but whatever the reason, the result is likely to be the same. The adoptive parents do not want to talk about the birthparents and, if they do talk about them, are often unable to do so in nonpejorative terms. Negative messages about the birthparents and about being adopted are thus 
transmitted to the adopted child. For adolescent adoptees, parents' insecurities may result in a loss of feeling of security in the relationship which in turn interferes with the development of a positive self-image.

In the absence of facts about his/her birthparents and the situation which led to being relinquished for adoption, the child is likely to create a story, often more negative and much more damaging to his/her self-esteem than the true story (Small, 1987). Telling the child about being adopted "really means being emotionally prepared for the questions when they come, interwoven with early sex instruction. The basic, often unspoken question is nearly always, 'Why did my own mother not keep me?" (Stone, 1972, p. 126). When the child does not ask, parents need to be able to bring up the subject, because the child is certain to be wondering. Open communication between the parent and child are necessary at all stages, and parents who have practiced this will be better prepared for coping with their child's adolescence.

All family members bring to the family their own unique blend of genetic and experiential factors. Recognition and acceptance of this is essential for individuation and growth of the family members (Satir, 1967). In addition to the way they relate to each other, the family must relate as a unit and individually to other "systems." For adoptive families, there are agencies to deal with at some point in the adoption process and the adopted child's biological family, 
whether real persons or "ghosts." The adoptive family can choose to include them in the family system or to attempt to keep them closed out.

There are other ghosts in an adoptive family's constellation. The-wife (or husband)-I-hoped-to-be is an important one for infertile persons who may feel guilt, shame, anger, and/or anguish because they cannot produce children. The-child-I-hoped-to-have is another ghost in the adoptive family system, an ideal child whose image may be transmitted to the child in the manner of parental beliefs, to the detriment of good parent-child relations. Adoptive parents whose family system is not flexible enough to accommodate these "outsiders" or who are heavily invested in being just like a biologic family may experience considerable stress.

The feeling of being cut adrift from one's genetic roots is sometimes experienced by adoptees as genealogical bewilderment. "The desire to know one's biological origins and parentage results from a deeply felt psychological and emotional need, a need for roots, for existential continuity, and for a sense of completeness" (Colon, 1978, p. 302). Since a sense of continuity over time is part of one's identity, adopted adolescents may have difficulty in identity formation without information about their birthparents. 
The adoptive family may experience increased stress when the adolescent is highly motivated to learn more about his/her genetic origins. The parents feel threatened and rejected, and may become defensive. Those adoptive parents who have been willing to see the birthparents as part of the family system from the beginning will be in a better position at this point. Those who are prepared to seek outside help or already have a support network of other adoptive families will find it even easier to keep communication lines open between themselves and their teenager.

Adoptive family support groups are usually seen as helpful by those who belong. The reasons they give include consciousness raising about adoption issues and knowing other adoptive parents and adopted children. "Such groups seem particularly important to independent adopters who...may not have the opportunity to talk about the issues concerning the adoption with anyone else" (Meezan, Katz \& Russo, 1978, p. 93). Yet only one-quarter of the sample of independent adopters in the study by Meezan et al were members of an adoptive parent group.

Time-limited groups for adoptive parents can be helpful. Digiulio (1979) reports that her goals in leading groups are to provide support, "lessen the member's sense of isolation...bring about changes in attitudes and feelings, facilitate coping skills, and provide empathy with the 
adoptee... and the biological mother". Upon completion of the series, all members of the group who evaluated the experience found the program to have met their needs in varying degrees.

A structured group for adopted adolescents and their parents, meeting separately, was found by Pannor and Nerlove (1977) to meet many of the needs of both groups. The teens were able to ask questions they were unable or reluctant to ask their parents, and found support in knowing other teens had many of the same questions. The parents were given the opportunity to "differentiate those problems attributable to adoption and those attributable to the teenager's normal efforts to separate... and achieve ego identity" (Pannor \& Nerlove, 1977, p. 538). All participants in the groups found that participating in the group had facilitated communication at home.

\section{ADOPTION DYNAMICS AND IDENTITY}

Hoopes et al have reported, based on study results published in 1972, 1982, and 1985 that "the overwhelming majority of adoptions can be considered successful" (Stein \& Hoopes, 1985, p. 1). "Successful" is defined by stein and Hoopes as being the satisfactory achievement of "emotional adjustment as measured by an assessment of ego identity" (p. 25). In their study of 50 adopted and 41 nonadopted adolescents, stein and Hoopes summarized their findings to 
indicate that "adopted subjects were not found to have greater difficulties along the dimension of identity formation than nonadopted subjects, that is, adoptive status in and of itself was not predictive of greater stress among adolescents in this study $(1985$, p. 46). "For the most part, successful outcome must be interpreted to mean that these children, in both cognitive and emotional areas, demonstrate functioning within the normal range and show no significant differences from biological children" (Hoopes, 1990, p. 153).

In a Swedish study (Bohman \& Sigvardsson, 1990), the authors wrote of positive vs. negative outcomes, based on the children's adjustment and school achievement. Parent and teacher observations and grades were used to measure adjustment while the subjects were in school, and military and criminal justice system records were searched when the subjects were eighteen and twenty-three years old.

According to Bohman and Sigvardsson (1990), "The long-term prognosis for adopted children is in no way worse than for children in the general population, provided that the adoptive home is psychologically prepared for the task of rearing a nonbiological child" (p. 104). They came to this conclusion following a study of 624 children in Sweden, divided into three categories: those placed for adoption shortly after birth, those whose birthmothers decided to single parent, and those placed in long-term foster care 
placements which ultimately resulted in adoption. children in the first category did significantly better on several measures of adjustment as adolescents.

The authors suggest that lack of preplacement preparation among the foster-adopt parents for parenting a nonbiological child may have contributed to the negative outcomes for children in this group (Bohman \& Sigvardsson, 1990). Preplacement preparation for parenting an adopted child may include practical and attitudinal readiness for discussing their adoption, including the child's birthparents, with the adopted child.

During the assessment and placement process, most adoptive parents experience feelings of helplessness, vulnerability and lack of control over their lives. In 1963, Humphrey and Ounsted estimated that about $60 \%$ of those applying to adopt are doing so because of infertility, and the rate of infertility has increased in recent years. Resolve, Inc., a support network for infertile couples, estimates that one out of six couples in the United States-as many as five million couples--are struggling with infertility. As prospective adoptive parents, infertile couples may experience increased anxiety, since it often leaves them feeling inferior and less in control of their lives than other couples. As the adopted child grows, talking about adoption is likely to be painful if these 
anxieties have not been addressed, preferably before placement.

Unwillingness to address emotionally painful topics may be one reason prospective adopters choose not to adopt through an agency, although it is seldom mentioned openly. In a study by Bluth (1967), couples who chose to adopt independently did mention reluctance to meet possible agency requirements for a medical investigation of childlessness. Agency requirements which the couple felt they could not meet were most often listed as "factors believed to have played a part in their decision to adopt independently" (Bluth, 1967, p. 510). However, in the Meezan (1978) study, only one out of six of the couples who looked into agency adoption were discouraged from applying because they did not meet agency requirements.

Conditions which the couple wished met but believed that an agency would not meet were also listed in the Bluth (1967) study as a reason for adopting independently. The agency's requirements or ability to meet the requirements of the prospective adoptive parents is often guesswork on the part of the prospective adopters. Meg Schneider says she called two agencies before deciding to adopt independently (Michelman \& Schneider, 1988). In Bluth's (1967) study, 43\% (9) of the couples who adopted independently did not even make inquiries at an agency. 
Whether the decision to adopt independently is "based on agency screening devices or on the couples' private reluctance, the fact remains that little if any meaningful assessment of their parental capacities was made prior to their becoming parents" (Bluth, 1967, p. 512). The attitude on the part of both the agencies and adoptive parents that the agencies' role is to screen applicants, has done a disservice to adoptive families.

Prospective adoptive parents who are reluctant to submit to the screening process lose the opportunity to participate in preplacement preparation for parenting an adopted child. Lack of awareness of the importance of this preparation is obvious in the how-to instruction books on adoption. Michelman and Schneider (with van der Meer, 1988) state that they have helped hundreds of prospective adopters "who agree that one of the most attractive things about private adoption is that they have much greater control than they would have in an agency adoption" (p. 8). The incentives for adopting independently usually mentioned include a possibly shorter wait for a baby, a possibly less costly adoption, circumvention of agency requirements, and greater control over the adoption process (Michelman et al, 1988 ; Rundberg, 1988).

The implication is that agencies should have less control. The possibility that the adoptive parents might be better prepared for adoptive parenthood by working with an 
agency is not considered. The fact that adoption is a lifetime experience for both the parents and the child is missed. During just the first year as adoptive parents, the following tasks confront most families: coping with uncertainty and anxiety related to the placement process; finding appropriate role models and developing realistic expectations regarding adoptive parenthood; coping with the social stigma surrounding adoption; developing secure attachment relationships while waiting for finalization.

At all stages of the adopted child's life, parents have the task of creating an atmosphere in which questions about adoption can be freely explored. This is a difficult task for many adoptive parents. They want to pretend that their child was born to them, that their family is just like everyone else's. They do not want to open their family system to outsiders--agencies or support groups, for example. Their adopted adolescent is causing such upheaval in the family that they wonder if they will survive. Most families do, the parents as well as the children. For some, however, it is easier than for others. It appears that the process is easier for those who have preplacement preparation, open family communication on the topic of adoption, willingness to accept differentness, and some permeability or elasticity of their family system. 
CHAPTER III

METHOD

This exploratory research was undertaken in an attempt to provide social work professionals and adoptive families with a better understanding of factors which might facilitate adolescent adoptee identity formation, measured as positive self-image. The Delaware Family Study showed that the adopted adolescents in their sample had no more negative self-image than the nonadopted adolescents. There are some ways, however, in which the DFS sample does not appear to be representative of all adopted youths. One is the participation in a longitudinal study. These families may have a more open family system and be able to talk more openly about adoption. It is also possible that those families who remain in a longitudinal study while their children grow from birth to adolescence are those who experience the least difficulty within their family.

The DFS sample has a low rate of divorce in the families. There also are no out-of-home youth in the DFS sample, and there are no adopted adolescents who were placed for adoption independently. This study was set up to use two of the three instruments and the same procedures as the 
DFS but with a sample which may be more representative of the population of adolescent adoptees.

\section{SUBJECTS}

The sample for this study was selected from volunteers 14 to 18 years of age who were adopted as infants. The mean age of the sample was 16.5 years; the modal age, 17 . The two youngest volunteers were starting the ninth grade. One seventeen-year-old and three of the eighteen-year-olds were out of high school; two were full-time college freshmen. There were 12 female subjects and 6 males. Volunteers were screened to include only those with at least average intellectual functioning. No attempt was made to screen volunteers according to how well adjusted they appeared to be.

Volunteers were secured in the following manner: one responded to an advertisement in a student newspaper (Ads were placed in the student newspapers of five Portland area high schools). Two responded to the advertisement in the Portland State University student newspaper and the younger sibling of one of these was then recruited. Three responded to notices posted in several more high schools in the Portland area, and three to a notice at an international adoption conference. Three responded to notices which were included in mailings to adoptive families and adoptive family support groups. Local adoption agencies were also 
contacted for assistance, but only one was willing and able to locate families whose placements took place fifteen or more years ago (resulting in one volunteer). The other five subjects were located by talking to friends and neighbors. Initially, no monetary reinforcement was offered. After a time, subjects were recruited with an offer of $\$ 3.00$, then $\$ 5.00$. At the end, volunteers were told they would be paid $\$ 15.00$. A few subjects appeared to be motivated largely by the "reward," but most adopted youth apparently do not find these amounts to be enough incentive.

There were 18 volunteers, 12 were placed by an agency and 6 were adopted independently (directly from the birthmother or through an intermediary such as an attorney). This is partly a reflection of sampling bias, but it may also reflect the actual occurrence of slightly more agency infant adoptions than independent infant adoption. In the 1987-88 record-keeping year, the most recent for which this breakdown is available in oregon, the adoptions of children birth to three years old were $42.6 \%$ independent and $57.4 \%$ public and private agency.

The subjects include 8 placed transracially, all with white parents, all from foreign countries: 3 Korean, 3 Vietnamese, 1 Bangladeshi, and 1 Honduran. Again, this reflects the reality of adoptions, since infant adoptions in the past twenty years have included a large number of intercountry/transracial adoptions (Simon \& Altstein, 1987). 
The same-race adoptions include 1 black and 9 white families. Thirteen of the subjects were living at home, while 4 were independent and 1 was in a foster placement. No attempt was made to determine the family's socio-economic status. There were three adopted sibling pairs, none biologically related. Thirty-nine percent (7) of the subjects had divorced parents. Only one subject did not have siblings in the adoptive family. Five subjects had adopted siblings only; three, only siblings born to the adoptive parents; eight, both adopted and biological.

It is recognized that reliance on volunteers incurs sampling bias. For instance, volunteers may be more likely to fall into one of two extremes--those who are angry and want to express negative feelings about adoption or those who are especially happy about being adopted. However, determining which adolescents are adopted and obtaining their parents' permission to participate in the study cannot be done in a way that would create true random sampling. It is intended only that this sample should be more representative of adopted adolescents in the general population that any which have heretofore been obtained from clinical groups or adoption agencies cohorts.

It is interesting to observe what types of people volunteered. Adults in their twenties ignored the published guidelines and called to see if they could be in the study, and emancipated youth responded. older adults called 
because they were interested in the subject themselves or wanted to get information for someone else. High school students who volunteered mostly got in touch through an intermediary adult, often their adoptive mother or father. Apparently, youth do not feel comfortable talking about being adopted with a stranger, perhaps not with anyone at all. Unfortunately, attempts to find out what reasons the teenagers have for being reluctant to talk about being adopted were not successful.

\section{PROCEDURE}

The subjects were interviewed individually in a variety of locations. To increase the subjects' comfort level, they were offered the options of being interviewed in their home, at school, or in another setting of their choice. All subjects were interviewed by the author. Completion of the three instruments required at least forty minutes; some subjects needed twice as much time.

Subjects were assured that their responses would be confidential, both in a written consent form (Appendix E) and orally, and the point was made that this includes not sharing anything with their parents. Parents of volunteers under eighteen, and those eighteen-year-olds still living at home, also signed a consent form (Appendix E). Demographic information was collected by the interviewer during the initial contact and at the interview. 
INSTRUMENTS

A modified Social Atom task (see Appendix A) originating with J. L. Moreno and modified by stein and Hoopes (1985) was administered first. This is a nonverbal, low-structure means of assessing the relative importance (degree of influence) of other persons in the subject's life, as well as the degree of intimacy in his/her interpersonal relationships and networks. The average time required for this task is 5 to 10 minutes. It is suitable for use with children, youth and adults. Administering the Social Atom is relatively simple, but scoring it requires considerable skill and knowledge of the constructs being tested. There are no sociometric norms for adolescents, but Stein and Hoopes (1985) found that this instrument correlated well with all three of the other instruments used in their study and indicated some interesting trends.

The offer Self-Image Questionnaire (OSIQ) was administered second. This instrument was designed for use with adolescent boys and was normed on a group of over 300 boys, after being pretested on two smaller groups, one a clinical group and the other consisting of "normal" boys, to ascertain that it did in fact distinguish between the two. It has since been normed on a similar group of girls and separate forms are provided for male and female subjects. Concurrent validity was satisfactory when the OSIQ scores were compared with the Bell Adjustment Inventory scores for 
conceptually parallel scales. It is a Likert-type pencil and paper test intended for use with youth ages 13 to 19 and takes 15 to 30 minutes for the subject to complete (Offer, 1969).

The Semi-structured Interview was the last instrument administered. It was designed by stein and Hoopes (1985) and includes some forced choice and some short answer questions; some sections are specifically for and administered only to adoptees (see Appendix B). The average administration time is approximately 25 minutes. The Interview was included

to enrich the self-report measures by providing a phenomenological account of how adolescents view themselves in different contexts... Intercorrelations of the dependent ego identity measures revealed significant relationships both within and between the various measures in the expected directions... The correlations between the Interview subfactors and the OSIQ Overall Average Self score...lends validity to the Interview as a measure of adjustment in adolescents. (Stein \& Hoopes, 1985, p. 33)

The Tan Ego Identity Scale was used by Stein and Hoopes to validate the Interview but was not included in this study. The possibility of reduced reliability due to interviewer factors has been minimized by using mostly forced choice questions which do not require interviewer interpretation. Administering and scoring this instrument requires some training on the part of the administrator and some understanding of the constructs being measured. 
The Interview was modified slightly for this study by replacing short answer questions with forced choice versions and adding questions to measure adoption-related selfperceptions (See Appendix B). Two adoption status questions, \#15 \&\#17, were added to Part $I$, which is not scored and contains only questions about adoption. Part II, family relatedness, was left intact; \#32 was omitted because there were no nonadopted subjects in this study. Part III, peer relations and Part IV, school performance, also had no changes in scored questions. Part $V$, with questions related to the subjects' feelings about themselves, was modified to focus upon the "adoptedness" aspect of self-esteem.

\section{EXPERIMENTAL DESIGN}

In previous studies, the simple fact of having been adopted has been the independent variable, with emotional adjustment, family relationships, etc., being the dependent variable. In this study, since all subjects are adopted, the method of placement is the independent variable with success/relative ease of identity formation, including self-esteem, and family relationships as the dependent variables. Means, standard deviations, Kruskal-Wallis Chi Square, and $t$ tests were used to analyze the data. 


\section{LIMITATIONS}

The difficulty in securing subjects and the consequently small number of units of data to compare resulted in the most serious limitations to this study. Identifying adopted adolescents through any method except by soliciting volunteers is generally not possible. This is because being adopted is personal information which cannot be revealed without invasion of privacy or a breach of confidentiality. Prevailing social mores still insist on secrecy for all parties in an adoption unless the individual member of the triad wants to talk about it. Unfortunately for this research, adopted teens seem reluctant to volunteer.

It appears that those who cannot hide their adopted status and have been accustomed to discussing it were most likely to volunteer, thus the fairly high percentage of subjects who were adopted transracially. This has a side effect of increasing the percentage of volunteers adopted through agencies, since the majority of transracial placements in the United States are arranged by intercountry agencies (Simon \& Altstein, 1987).

Initial contacts used to solicit volunteers also tended to tap into agency-related adoptions, or at least families who are part of a formal support group. Finding adolescents who were adopted independently proved to be extremely 
difficult, resulting in a sample size too small for the results to be generalizable.

\section{OTHER QUESTIONS FOR EXPLORATION}

The factors which draw adoptive parents to independent adoption versus agency adoption include some factors which influence their parenting style in a way that affects the adopted child's self-perception and self-esteem. That is, the agency adoptors would have more flexible and more permeable boundaries for individuals in the family and for the family system.

The sample of adopted adolescents in the DFS was not representative of all adopted adolescents in the U.S., for two reasons. All of the subjects were placed by the same agency in the same geographic area. All of the subjects were part of a longitudinal study. The assumption was that there would be differences, possibly significant, in a group of adopted adolescents from around the country, placed by a variety of agencies, especially if the adoptive families had had no contact with an adoption agency or adoptive family support group since the adoption was finalized.

Alterations in the questionnaire were made because it was assumed that adopted children feel different from nonadopted children, that this can have a negative impact on the child's self-esteem, and that knowing other adopted persons might mitigate the negative impact. 
Fourth, transracial adoption in and of itself does not negatively affect the child's self-esteem and identity formation.

Agency adoptions involve at least minimal pre-placement preparation for parenting an adopted child. Even when agencies have no formal adoption preparation process for prospective adoptive parents, the homestudy process may serve the purpose. 
CHAPTER IV

\section{RESULTS AND DISCUSSION}

\section{MAJOR FINDINGS}

Although the findings of this research do not support, with statistically significant data, the hypothesis which was the basis for the research, several of the other questions explored were supported. Due to the small size of the sample, no conclusions can be stated with regard to the population of adopted adolescents, but the findings suggest that further investigation might be profitable.

A profile of the sample's performance on the Interview and the Offer Self-Image Questionnaire (OSIQ) is presented in Table I. On the OsIQ, "a score of 50 signifies a score equal to the appropriate normal reference group mean. A score lower than 50 signifies poorer adjustment than that of normals. A score higher than 50 signifies better adjustment" (Offer, Ostrov \& Howard, 1982, p. 5). Although the means scores for all subjects are below 50 in all areas except Social self, they are well within the normal range. on all tables, Interview scores are reported as raw scores. Scores on the offer Self-Image Questionnaire have been converted to scale scores with a mean scale score of 50 and a standard deviation of 15. In all comparisons of two 
groups, the tests of significance are a two-tailed $\underline{t}$ test for nonpooled variance. A Kruskal-Wallis H (Chi Square) was used to test significance with three or more groupings of subjects. When using these statistical analyses with small samples, it is important to keep in mind that the analysis becomes less powerful as the sample becomes smaller. This means that differences which might be significant will be rejected. Looking for clear trends may offset this somewhat.

\section{TABLE I}

MEAN SCORES AND STANDARD DEVIATIONS

ON THE INTERVIEW AND THE OSIQ

FOR ALL SUBJECTS $(\mathrm{N}=18)$

\begin{tabular}{|c|c|c|c|c|}
\hline & Mean & S.D. & $\begin{array}{c}\text { Possible } \\
\text { Range }\end{array}$ & $\begin{array}{r}\text { Actual } \\
\text { Range }\end{array}$ \\
\hline $\begin{array}{l}\text { Interview Total Score } \\
\text { Family Factor } \\
\text { Peer Factor } \\
\text { School Factor } \\
\text { Self-Esteem Factor }\end{array}$ & $\begin{array}{r}67.56 \\
25.89 \\
19.94 \\
9.11 \\
12.61\end{array}$ & $\begin{array}{l}6.85 \\
3.82 \\
2.69 \\
2.14 \\
1.58\end{array}$ & $\begin{array}{r}29-85 \\
11-33 \\
8-24 \\
4-12 \\
6-16\end{array}$ & $\begin{array}{r}65-84 \\
19-33 \\
13-23 \\
4-12 \\
9-16\end{array}$ \\
\hline $\begin{array}{l}\text { Offer Self-Image Questionnaire } \\
\text { Overall Average Self Score } \\
\text { Psychological Self Score } \\
\text { Social self Score } \\
\text { Sexual self Score } \\
\text { Family Self Score } \\
\text { Coping Self Score }\end{array}$ & $\begin{array}{l}\text { (OSIQ) } \\
47.25 \\
45.33 \\
51.37 \\
44.57 \\
44.33 \\
49.12\end{array}$ & $\begin{array}{r}11.74 \\
11.13 \\
8.39 \\
18.59 \\
16.00 \\
9.90\end{array}$ & & \\
\hline
\end{tabular}

${ }^{1}$ The Interview Total score consists of Parts II through $V$. Questions designated on the original Interview as being for adopted subjects only were not scored. In order to make the scores for this sample comparable with the DFS, Question \#22 was also dropped. 
Accuracy may also be doubtful with fewer than six subjects in a cell, limiting the analyses possible with the subjects in this study.

When the study's sample was divided according to method of placement, there were 12 Agency and 6 Independent subjects (Table II). On all areas of the Interview--Total and each of the four Factors--the Agency group had higher scores, the largest difference being on the Peer Factor. However, on the OSIQ the Independent group had higher scores on three of the five self scores, as well as the overall Score. None of the results reached significance. It seems that no conclusion can be drawn from these data about the relationship between method of adoption placement and the self-image of adopted adolescents.

\section{TABLE II}

COMPARISON OF SCORES ON THE INTERVIEW AND THE OSIQ FOR AGENCY AND INDEPENDENT SUBJECTS ( $\mathrm{N}=18$ )

Agency Independent df $t \quad p$ $(\mathrm{N}=12) \quad(\mathrm{N}=6)$

Interview Total Score

Family Factor

Peer Factor

School Factor

Self-Esteem Factor
65.00

26.17

20.67

9.33

12.67
68.83

25.33

18.50

8.67

12.50
$6 \quad .95$ ns

$6 \quad .36 \mathrm{~ns}$

$\begin{array}{lll}7 & 1.45 & .19\end{array}$

$7 \quad .53 \mathrm{~ns}$

5.16 ns

Offer Self-Image Questionnaire (OSIQ)

Overall Average

self score

Psychological

Self Score

Social Self Score

46.40

49.00

$14.50 \mathrm{~ns}$

Sexual Self Score

46.00

43.90

50.63

52.84

Family Self Score

46.30

41.00

41.30

50.50

48.20

51.04

$8.35 \mathrm{~ns}$

15.62 ns

$5 \quad .43$ ns

Coping Self Score

15

$1.39 \cdot 18$

$14 \quad .65 \mathrm{~ns}$ 
It was hypothesized that families who adopt through an agency would have a more permeable family system than those adopting independently, being more willing to "invite others in." Because of this, it was expected that the Agency families would be more willing to seek help from an agency or peers proactively, as a positive, possibly preventive step. For instance, it was expected that these families would be more likely to belong to an adoption support group at some point.

For this sample, this expectation turned out to be appropriate. Among the six subjects adopted independently, only one said "Yes" to the question, "Has your family ever belonged to an adoption support group?" This subject and her parents had participated in an adoptee rights group. Among the twelve Agency subjects, eight (67\%) said "Yes" and four ( 338 ) said "No" when asked if they had belonged to a support group. The family of one of the four subjects who had not belonged to a support group had sought counseling with their daughter. The other three Agency subjects whose families had not had support group membership were among the out-of-home subjects.

Table III shows the average scores of the sample when divided according to Support Group or No support Group. In all areas, the scores for the support Group sample were equal or higher, but the differences were statistically insignificant with one exception. Results on the OSIQ 
scores for Psychological Self, combined with the trend of the other scores, provide support for the idea that belonging to a support group is beneficial.

TABLE III

COMPARISON OF SCORES ON THE INTERVIEW AND THE OSIQ FOR SUPPORT GROUP AND NO SUPPORT GROUP SUBJECTS $(\mathrm{N}=18)$

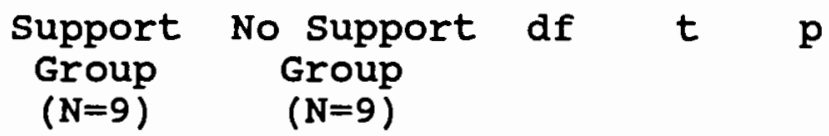

Interview Total Score

Family Factor

Peer Factor

School Factor

Self-Esteem Factor
69.11

26.22

20.22

9.67

13.00
66.00

25.56

19.67

8.56

12.22
13

14

13

15

10
$.96 \mathrm{~ns}$

.36 ns

$.43 \mathrm{~ns}$

1.11 ns

1.05 ns

Offer Self-Image Questionnaire (OSIQ)

overall Average

Self Score

Psychological

Self Score

Social Self Score

Sexual Self Score

Family Self Score

Coping Self Score

$\begin{array}{ll}50.10 & 44.40 \\ 49.24 & 41.40 \\ 51.20 & 51.53 \\ 44.90 & 44.30 \\ 47.80 & 40.90 \\ 51.00 & 47.28\end{array}$

15

$1.05 \mathrm{~ns}$

51.00

47.28

15

13

12

$1.55 \cdot .14$

$.08 \mathrm{~ns}$

$.06 \mathrm{~ns}$

15

$.91 \mathrm{~ns}$

14

.78 ns

It was also assumed that adopted children feel

different from other children and benefit from positive contacts with other adoptive families, such as those often found in adoptive family support groups. Subjects were asked if they know other families with adopted kids (Interview question 15) or adopted adults (Interview question 57) and, in both cases, if this affects the way they feel about themselves. None of the subjects said that knowing someone else who is adopted affects their opinion of 
themselves negatively. Only 2 subjects said they did not know other adoptive families; 10 subjects did not know adopted adults. None of the subjects felt that not knowing other adoptees affected them negatively. On the other hand, 3 subjects said that knowing other adopted kids did affect them positively and 1 subject said that knowing an adopted adult had a positive effect on that subject's feelings about self.

One motivation for this research was the belief that the Delaware Family Study sample of adopted adolescents was not representative of the population of adopted adolescents. Even when limiting the population under consideration to those placed for adoption as infants in the United States, the DFS sample should not be taken as representative.

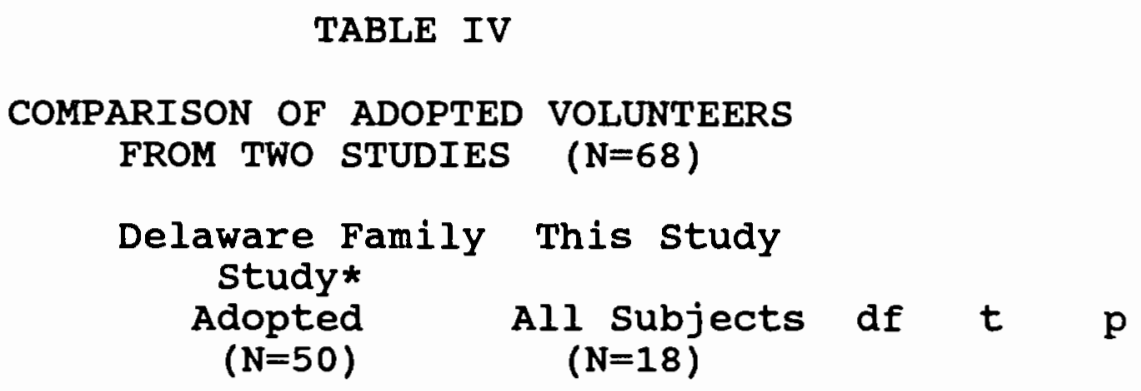

Offer Self-Image

Questionnaire

$\begin{array}{llllll}\text { Overall Average Self } & 51.34 & 47.25 & 28 & 4.65 & .000 \\ \text { Psychological Self } & 53.02 & 45.33 & 37 & 8.90 & .000 \\ \text { Social Self } & 50.09 & 51.37 & 43 & 1.87 & .03 \\ \text { Sexual Self } & 45.81 & 44.57 & 24 & .90 & .19 \\ \text { Family Self } & 52.38 & 44.33 & 30 & 5.16 & .000 \\ \text { Coping Self } & 55.78 & 49.12 & 36 & 3.71 & .000\end{array}$

*Stein \& Hoopes, 1985, p. 36 . 
It was not possible to compare the Interview scores for the DFS with those from this study due to changes in the Interview. However, comparison of the DFS Adopted sample and the subjects from this study, using the OSIQ scores, yielded significant differences on five Self scores.

A comparison of the OSIQ scores of the nonadopted sample from the DFS and the adopted sample from this study (Table V) indicates that the author was correct in questioning whether other samples of adopted adolescents would compare as well with the DFS nonadopted sample as their adopted sample did.

TABLE V

COMPARISON OF NONADOPTED AND ADOPTED VOLUNTEERS

FROM TWO STUDIES ( $\mathrm{N}=59)$

Delaware Family This study Study* Nonadopted

$(\mathrm{N}=41)$

All subjects df $t$ $(\mathrm{N}=18)$

Offer Self-Image

Questionnaire

$\begin{array}{llllll}\text { Overall Average Self } & 53.63 & 47.25 & 28 & 7.11 & .000 \\ \text { Psychological Self } & 51.54 & 45.33 & 37 & 6.61 & .000 \\ \text { Social Self } & 53.81 & 51.37 & 43 & 3.11 & .002 \\ \text { Sexual Self } & 47.82 & 44.57 & 24 & 2.38 & .003 \\ \text { Family Self } & 53.36 & 44.33 & 30 & 7.24 & .000 \\ \text { Coping Self } & 55.78 & 49.12 & 36 & 7.91 & .000\end{array}$

‡Stein \& Hoopes, 1985, p. 36 .

If the adopted adolescents that made up the sample for this study had been used in the DFS, they could not have concluded that there is little difference between adopted 
and nonadopted adolescents in the areas measured by the OSIQ. It appears that more extensive research is needed. The sample for this study varied from the DFS in two ways. One was the inclusion of adopted subjects placed independently, which has already been discussed. The other difference was the inclusion of transracially adopted subjects. Studies of transracially adopted persons present a mixed picture. Some indicate that being reared by white parents creates a problem in the area of identity formation for children of color. Other findings indicate that being adopted transracially may not be, in and of itself, detrimental to identity formation (McRoy \& Zurcher, 1983; Shireman, 1988; Simon \& Altstein, 1987).

MCRoy and Zurcher (1983) found in their early study of transracially adopted children that their subjects "exhibited typical adolescent relationships with their parents, siblings, teachers, and peers. similarly,...they reflected positive feelings of self-regard...The quality of parenting is more important than whether" the child has parents of the same race (p. 138).

The Family Life Project (Shireman, 1988) has been a longitudinal study of children adopted transracially and by same-race parents, with the addition of nonadopted children for comparison purposes. As the subjects enter adolescence, the Family Life Project found that "transracially adopted children seem as well integrated into their families, seem 
to be doing as well in school, and seem in general to be as well adjusted as other adopted children" (p. 24).

In this study, transracially adopted children were not distinguished from same-race adopted children except in analyzing the data in Table $\mathrm{V}$. One set of scores is worth noting. This is the much lower sexual self average score for the Transracial group. The Sexual Self section of the OSIQ "concerns itself with the adolescent's feelings, attitudes, and behavior towards the opposite sex... A low standard score means a relatively conservative attitude towards sexuality. A high standard score means relative openness to sexuality" (Offer, 1982).

It may be that this finding supports the commonly-held belief that opposite-sex relationships are potentially problematical for transracially adopted adolescents. Adolescents who are deterred from venturing into oppositesex relationships because of race differences may measure as "conservative." The slightly higher age of the Same Race group might help explain the difference on the sexual self Score (Same Race--16.7 years vs. Transracial--15.9). Older subjects, in general, had higher sexual self scores. It should also be noted that six out of ten (60\%) of the same Race subjects have divorced parents; only one of the eight Transracial subjects has divorced parents.

Comparing the children of divorced parents with those from intact families showed no statistically significant 
difference. The Family Self average score for the Intact families, however, was considerably higher than for Divorced families $(t=1.27, p=.22)$. Thus, the difference in Family Self scores between Same Race and Transracial subjects may be due to divorce dynamics as much as anything to do with race. The Sexual self average scores were higher for the Divorced group, possibly accounting for part of the difference between Same Race and Transracial groups.

\section{TABLE VI}

COMPARISON OF SCORES ON THE INTERVIEW AND THE OSIQ FOR SAME RACE AND TRANSRACIALLY

ADOPTED SUBJECTS $(\mathrm{N}=18)$

Same Race Transracial df $t \quad p$ $(\mathrm{N}=10) \quad(\mathrm{N}-8)$

Interview Total Score

Family Factor

Peer Factor

School Factor

Self-Esteem Factor
66.70

25.20

20.25

9.80

12.50
68.62

26.75

19.70

8.87

12.75
$15 \quad .61 \mathrm{~ns}$

$13 \quad .83$ ns

$15 \quad .44$ ns

15.43 ns

11.36 ns

Offer Self-Image Questionnaire (OSIQ)

Overall Average Self

Score

Psychological self Score

Social Self score

Sexual Self Score

Family self Score

Coping Self Score
45.70

42.50

51.72

50.10

41.10

49.43
49.20

48.80

50.90

37.70

48.30

48.70
$13 \quad .59$ ns

151.23 ns

$10 \quad .18$ ns

$151.51 \cdot .15$

$12.91 \mathrm{~ns}$

$13 \quad .14$ ns

A final note about the same Race and Transracial groups concerns support group participation. Seven of the 8 subjects adopted transracially belonged to support groups; 8 of the 10 Same Race group did not. Since it appears that belonging to a support group may be beneficial for adopted 
children's development of a positive self-image, it may be that belonging to a support group mitigated the possible negative effects of transracial adoption for these subjects.

The subjects were divided into two groups based on the median split of Family Factor scores from the Interview and the means compared. In the DFS, striking differences between the two groups were found, with the higher mean score of the Satisfactory group being significant at the .001 level. The subjects in this study had only a small difference between the mean Family Factor scores of the Satisfactory and Unsatisfactory groups (albeit in the same direction as the Delaware Family study). Interestingly, five of the six (83.3\%) Independent subjects were in the Unsatisfactory Family Relationships group.

Openness of communication about the subject's adoption was determined by the subjects' responses to Question 9 on the Interview. Only 3 subjects said that their adoption is never or very rarely mentioned. All 3 also said, in answer to Question 12 , that their adoption is not discussed enough, in their opinion. In contrast, the 6 subjects who said that their adoption is only occasionally discussed also said that they are satisfied with this level of frequency. None of the subjects said that their adoption is discussed too much. Measuring family relationships and their influence on identity another way, the social Atom indicates how influential parents and others are in the adolescent's life 
and how close s/he feels to these same persons. When the subjects were asked to list people who are or have been most socially and emotionally influential their choices were categorized as Parents Only, Peers Only, Parent and Peer, or other combination. In this study, all of the subjects' highest influence categories were either Parent and Peer, or Other: no subject's Highest Influence category was Parent only or Peer only. The other subjects' most highly scored individuals included unrelated adults only ( 2 subjects), siblings only ( 2 subjects), and family--all categories of relatives other than parent ( 2 subjects).

\section{TABLE VII}

RELATIONSHIP BETWEEN CATEGORY WITH HIGHEST

INFLUENCE SCORE (SOCIAL ATOM) AND OVERALL IDENTITY $(\mathrm{N}=18)$

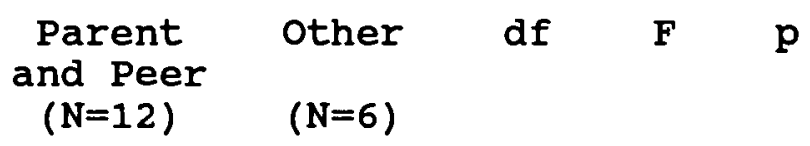

Interview Total Score

Family Factor

Peer Factor

School Factor

Self-Esteem Factor

$\begin{array}{rr}69.83 & 63.05 \\ 26.58 & 24.50 \\ 20.75 & 18.33 \\ 9.92 & 7.50 \\ 12.58 & 12.67\end{array}$

$\begin{array}{rrr}6 & 1.81 & .12 \\ 5 & .83 & \mathrm{~ns} \\ 8 & 1.84 & .10 \\ 10 & 2.68 & .02 \\ 6 & .08 & \text { ns }\end{array}$

Offer Self-Image Questionnaire (OSIQ)

Overall Average Self

$$
\text { Score }
$$

Psychological Self Score

Social Self Score

Sexual Self Score

Family Self Score

Coping Self Score
52.18

49.32

53.75

46.20

48.80

53.39
37.39

37.30

46.61

41.30

35.40

40.58
$10 \quad 3.14 \quad .01$

$\begin{array}{lll}8 & 2.27 & .05\end{array}$

$\begin{array}{lll}11 & 1.91 & .08\end{array}$

$10 \quad .52$ ns

$\begin{array}{lll}6 & 1.46 \quad .19\end{array}$

$\begin{array}{lll}10 & 3.32 \quad .008\end{array}$ 
It is apparent that adolescents who have both peers and parents to whom they can look for help have a more positive self-image. The author expected that grandparents or older siblings might satisfactorily provide the parental role model, but the youth in this sample whose most influential persons were in these categories were among those with the lowest scores. Only one subject included a birthparent among the influential persons--one who had ongoing contact with the birthfamily following a reunion a few years ago. The Social Atom also measures categories of persons to whom the subjects feel closest. The categories are Parent only, Peer Only, Parent and Peer, and other. No statistical analyses of the data are reported because of the extremely small number of responses in the categories. Six subjects had Parents only closest to themselves; 4 subjects, Peer Only; 3 subjects, Parent and Peer; 5 subjects, Other. The breakdown on other is unrelated adults only ( 1 subject), siblings only ( 2 subjects), unrelated adult and peer (1 subject), and unrelated adult and grandparent (1 subject). The median scores of the subjects in the other category were consistently lower scores than any of the other groups.

Although there are some differences on specific scores between the DFS and this study, the general findings from the Social Atom are the same. "Results seem to reflect... the fact that high identity adolescents tend to have relational systems that include both parents and peers 
to whom they attribute both closeness and influence" (Stein \& Hoopes, 1985, p. 52) .

\section{ADDITIONAL FINDINGS}

How does this sample of adoptees perceive that their adoptive status affects different spheres of their lives, and how does that compare with other adopted adolescents? In the Interview, subjects were asked to respond in five areas-family, peer, social, self-esteem and academic--to questions such as, "Has being adopted had any effect on...?". Whereas there were three responses in this study under "significant negative effect," there were no such responses in the DFS. Family relationships had the highest number of negative responses in this study. Relationships with peers also appears to be, for some adopted adolescents, negatively affected by their adopted status.

Subjects were asked how similar they perceive themselves to be in physical appearance and personality to their adoptive families. Ten subjects said they are different in appearance; 8 said they are similar. Two of the transracially adopted subjects say they look very (1) or somewhat (1) similar to their adoptive parents. This may be denial of differences, or it may be that the family has been successful in helping the child to identify with the parents in the ways that they are similar. The Different group had 
higher scores in all categories, although none reached significance.

In regard to personality, 12 said their personality is similar to their family's; 6 said it is different. Only 1 subject said both appearance and personality is very different. Three subjects see themselves as being similar to their adoptive families in both appearance and personality. Most subjects felt they are like their adoptive family in only one dimension--either appearance or personality. No correlation was found between similarity (in either appearance or personality) and self-image scores.

All subjects were asked how old they were when they were told they were adopted. Fifteen of them said "Too young to remember." The other 3 said three years old ( 1 subject) and four years old ( 2 subjects). Fourteen subjects said they would choose to be told at the same age if given a choice; 1 said "earlier"; 3 said "later".

In response to the question, "Were you ever told why you were placed for adoption?" 11 subjects said "yes"; 7 said "no". Five of the No group were adopted intercountry and, presumably, the reasons the birthmother chose not to parent are unknown. When asked their reaction to being told that they are adopted (Question \#5), 17 of the subjects said they had little or no reaction. The subjects were instructed that if they had said "Too young to remember" as the age they were told they were adopted, that they should 
answer the question about their reaction based on the first time they remember being aware of what being adopted means. Only 1 subject chose the response "mildly depressed"; none said "Very upset".

In a 1973 study of adult adoptees searching for their birthparents, Triseliotis found:

The greater the dissatisfaction with the adoptive family relationship and with themselves the greater the possibility that they would now be seeking a reunion with the birth parents, whereas the better the image of themselves and of their adoptive parents the greater the likelihood that they were merely seeking background information." (in Sorosky et al, 1975. p. 23)

stein and Hoopes corroborated these findings in their study of generally well-adjusted adoptees. "Few adolescents interviewed (16 out of 50) actually wished to search for their biological parents, although all 50 adoptees studied expressed an interest in general background information, with health history heading the list" (Stein \& Hoopes, 1985, p. 57).

In response to Question 13 on the Interview, 3 subjects said they are actively seeking information about their birthparents with the intention of meeting them. One subject said "actively seeking information but with no intention of meeting" the birthparents. Ten subjects have wondered a lot but never tried to obtain information, 3 have already met one or both birthparents, and only 1 subject said "never wondered". On the other hand, 12 (67\%) of the subjects said that if they did seek information, they would 
want specific identifying information. In the DFS, only $32 \%$ actually wanted identifying information, but part of the difference may be due to the increased publicity adoptee rights have received during the past few years.

only 1 subject said it is doubtful that the adoptive parents passed along all the information they have about that subject's adoption, but 5 subjects are dissatisfied with the information they were given about their adoptions.

The 5 "Dissatisfied" subjects are all 17 or 18 years old, with an average age of 17.4. Apparently, older adolescents are more likely to want more information. Their mean Interview Total score is the same as the mean for the entire sample, but they tend to fall at one extreme or the other. Three are among the early emancipators and one has experienced an unplanned teen-age pregnancy. It is not possible to tell from these data whether there is a correlation between dissatisfaction with information about their adoptions and early emancipation or sexual acting-out. 


\section{CHAPTER V}

\section{SUMMARY}

\section{SUMMARY OF MAJOR FINDINGS}

This research was undertaken in an attempt to investigate a possible answer to the question, "Why do some adopted adolescents manage identity formation with no greater distress than nonadopted adolescents, while others experience considerable difficulty with the process? The Delaware Family study found no significant differences between the adopted and the nonadopted adolescents in their sample, but all of their adopted subjects were placed by an agency. Is there something about agency applicants and/or the way they parent their adopted children which eases those children's passage through adolescence? It is possible, of course, that children placed independently or by other agencies have inherent personality or character traits which mitigate against ease of identity formation, but it seems unlikely. It would be, in any case, extremely difficult to investigate.

In looking at the variables which might differentiate other adopted adolescents from the DFS sample, it seemed more likely that the preplacement preparation for parenting and the ongoing contact which the adoptive families had with 
the researchers would be of benefit to these adoptive parents and their children. Again, it is possible that there are inherent traits in persons who adopt through agencies which improves their "success rate" as adoptive parents. Again, this would be difficult to measure directly.

In looking for a behavior pattern on the part of the adoptive parents which would correlate, it appeared that openness of the family system and willingness to participate in a group situation might both be characteristics of families who adopt through an agency and participate in a longitudinal study. For that reason, this study was set up to look at both method of placement of the adopted child and the family's participation or nonparticipation in a support group.

In spite of the author's efforts to recruit volunteers, the final sample size was too small to provide generalizable, statistically significant results in the area under investigation. If the sample used in this study represents the population of adopted adolescents when divided by method of placement, we would have to reject the hypothesis in Chapter I. With a sample this small, failure to find a statistically significant difference does not prove the hypothesis to be false, but the mixed results do not even indicate a trend worth further investigation. 
When looking at the results of support Group versus No Support Group, the findings are more interesting. With this sample, there is a clear trend toward higher scores on the test instruments for those adopted adolescents whose families have had some involvement with a support group. However, no conclusions about the population of adopted adolescents and support group participation can be drawn from the results of this study.

There was one research question which the data clearly support, since the sample in this study is significantly different from the Adopted sample in the DFS. Clearly, the DFS sample is not representative of all adopted adolescents in the United States who were placed as infants. It may be that the DFS sample is more representative than the sample in this study. On the other hand, this sample seems to fall somewhere between the extremes usually reported. None of the subjects in this sample was institutionalized for pathological or deviant behavior, although 3 subjects (17q) might be said to fall within clinical populations. There were also some subjects who appear to be quite stable, welladjusted adolescents. The majority fell somewhere in between.

The sample's average Overall Self Score of 47.25 on the OSIQ is only slightly below the reference group mean of 50 , indicating generally average adjustment. Since the DFS sample was also "average" according to the osIQ yet 
significantly different from this study's sample, it would appear that more finely tuned test instruments are needed to measure where or what the differences are.

The results of this study agree with other findings that indicate that being adopted transracially does not necessarily mean more difficulty with identity formation. The only area in which this study's transracially adopted subjects were significantly different from those adopted by same-race parents was the sexual self score on the OSIQ. This may be due partly to dynamics within the family other than racial identity issues. It may also be, however, that this is the dimension which accounts for most of the difficulty in identity formation which has been noted in transracially adopted adolescents. In all other ways the differences between the Same Race and Transracial groups were insignificant.

The findings of this study seem to support the earlier findings that good family relationships are important. Having a parent to whom the adolescent can look for guidance appears to be more important than looking like one's parents. For youth who do not look like their parents, finding a way that they are alike in personality may help to meet the need for identification with the parents.

Compared with the DFS sample, a larger percent of this study's sample felt that being adopted impacted negatively on their lives, especially in the area of family 
relationships. As in previous studies, there appears to be some connection between family relationships and dissatisfaction concerning the information the adoptee has about genetic origins.

Subjects who said their adoption is never discussed also want to talk about it more. There is some interaction of family variables at work here. Two sibling pairs came up with different answers about openness in discussing adoption in their family--two subjects said their adoptions were more openly discussed than those subjects' siblings said theirs were. Perhaps this is because the parents volunteer more information to one child than another, or because one child asks more questions than the other, or simply differences between the siblings in perceptions and needs. Again, the sample was too small to make any useful statistical analyses of family relationship variables except the importance of having an influential parent in the adoptee's life.

\section{IMPLICATIONS FOR PRACTICE}

The findings from this study would have to be used cautiously when suggesting any application to social work practice. It may be that preplacement preparation and postplacement support group participation are beneficial for the adoptive family, especially for promoting a positive outcome for the child. 
The practice of discouraging transracial adoptions is not supported by the findings of this research. However, those involved in arranging transracial adoptions might be well-advised to provide families with assistance in the areas included in the sexual self on the OSIQ. This includes opposite-sex peer relationships as well as sexuality.

Finally, any assistance which can be given to adoptive families in promoting open and positive communication about adoption probably would be beneficial for the development of a positive self-image on the part of the adopted adolescent.

\section{DIRECTIONS FOR FUTURE RESEARCH}

Transracial adoption is of interest to a large number of people and is currently under investigation by others. Social work practice and the families living in transracial families could benefit from more specific investigations of the separate aspects of the self-system in adolescents and racial identity. Also, comparison of transracially adopted youth whose families had participated in a support group versus those who had not might yield interesting results.

Although the findings about support groups in this study were inconclusive, it appears that further research in this area might be profitable. Specifically, the manner in which support group participation may be beneficial would be 
useful information; facts to go with the theory would be helpful.

More research on the long-term effects of preplacement preparation seems indicated. At the present time, this is often available to prospective adoptive parents who are connected with an agency, but this would not have to be so. Some adoptive family support groups do adoption preparation classes. Investigation of the success rate for adoptions by "alumni" of these classes might be useful.

Getting through adolescence with a positive self-image is challenging for most children. For children who have been adopted, the process can be even more of a challenge. Most adopted adolescents successfully accomplish the stage of identity formation, but sometimes not without considerable pain for them and their families. As researchers investigate the factors in society, in families, and within individuals that may help or hinder successful adoptions, the benefits may be felt by all adolescents and their families. The adopted adolescents who helped with this study by being volunteers would like to think that they have contributed even a little toward that end. 
Ambron, S., Brodzinsky, D. \& Gormly, A. (1986). Lifespan human development. New York: CBS College Publ.

Andrews, R. (1978). Adoption: Legal resolution or legal fraud? Family Process, 17, 313-328.

Bluth, H. (1967). Factors in the decision to adopt independently. Child Welfare, XIVI(9), p 504-13.

Bohman, M. \& Sigvardsson, S. (1990). Outcome in adoption: Lessons from longitudinal studies. In Brodzinsky, D. \& Schechter, M. (Eds.), The Psychology of Adoption, pp. 93-106. Oxford: oxford Univ. Press.

Cadoret, R. J. (1990). Biologic perspectives of adoptee adjustment. In Brodzinsky, D. \& Schechter, M. (Eds.), The Psychology of Adoption, pp. 25-41. Oxford: Oxford Univ. Press.

Colon, F. (1978). Family ties and child placement. Family Process, 17, 289-312.

Conger, J. J. (1977). Adolescence and youth: Psychological development in a changing world. New York: Harper \& Row.

Digiulio, J. (1979). The "Search": Providing continued service for adoptive parents. Child Welfare, 58(7), $460-465$.

Erikson, E. (1968). Identity: Youth and crisis. New York: w. w. Norton.

Fahlberg, V. (1979). Attachment and separation. Michigan Dept. of Social Services, DSS Pub. \#429.

Hoopes, J. (1990). Adoption and Identity Formation. In Brodzinsky, D. \& Schechter, M. (Eds.), The psychology of adoption, pp. 144-166. Oxford: Oxford Univ. Press.

Humphrey, M. \& Ounsted, C. (1963). Adoptive families referred for psychiatric advice: $I$. The children. British Journal of Psychiatry, 109, 599-608. 
Katz, L. (1980). Adoption counseling as a preventive mental health specialty. Child Welfare, 59(3), 161-167.

Kennell, J., Voos, D. \& Klaus, M. (1976). Parent-infant bonding. In R. Helfer \& C. H. Kempe (Eds.), Child abuse and neglect. Cambridge, MA: Ballinger Publishing.

Kirk, H. D. (1984). Shared fate: A theory and method of adoptive relationships. Port Angeles, WA: Ben Simon publications.

Magid, K. \& McKelvey, C. (1987) . High risk: Children without a conscience. New York: Bantam Books.

Marcia, J. (1967). Ego-identity status: Relationship to change in self-esteem, "general maladjustment," and authorianism. Journal of Personality, 35, 118-123.

MCGillicuddy-De Lisi, A. (1985). The relationship between parental beliefs and children's cognitive level. In sigel, I. (Ed.), Parental belief systems, pp. 7-25. Lawrence Erlbaum Assc.: Hillsdale, NJ.

McRoy, R. G. \& Zurcher, L. A., Jr. (1983). Transracial \& inracial adoptees. Springfield, IL: Charles C. Thomas, Pub.

Meezan, W., Katz, S. \& Russo, E. M. (1978). Adoptions without agencies. New York: Child Welfare League of America.

Michelman, S. B. \& Schneider, M. F. with van der Meer, A. (1988). Private adoption handbook: A step-by-step quide to the legal, emotional and practical demands of adopting a baby. New York: Villard Books

Offer, D. (1969). The psychological world of the teenager: A study of normal adolescent boys. New York: Basic Books.

Offer, D., Ostrov, E. \& Howard, K. I. (1982). The Offer Self-Image Questionnaire for adolescents: A manual. Chicago: Michael Reese Hospital \& Medical Center.

Offer, D., Ostrov, E. \& Howard, K. I. (1984). Body image, self-perception, and chronic illness in adolescence. In Blum, R. W. (Ed.), Chronic illness and disabilities in childhood and adolescence (pp. 59-73). Grune \& Stratton. 
Offord, D., Aponte, J. \& Cross, L. (1969). Presenting symptomatology of adopted children. Archives of General Psychiatry, 20, 110-116.

Pannor, R. \& Nerlove, E. (1977). Fostering understanding between adolescents and adoptive parents through group experiences. Child Welfare, 56(8), 537-545.

Rundberg, G. (1988) How to get babies through private adoption. Bend, OR: Maverick Publications

Satir, V. (1967). Conjoint family therapy. Palo Alto, CA: Science \& Behavior Books.

Schechter, M., Carlson, P., Simmons, J. III, \& Work, H. (1964). Emotional problems in the adoptee. Archives of General Psychiatry, 10, 109-118.

Shireman, J. (1988). Growing up adopted: An examination of Major Issues. Chicago, IL: Chicago Child Care Society.

Simon, R. J. \& Altstein, H. (1987). Transracial adoptees \& their families: A study of identity \& commitment. New York: Praeger.

Small, J. (1987). Working with adoptive families. Public Welfare, 45, 33-41.

Sorosky, A., Baran, A. \& Pannor, R. (1975). Identity conflicts in adoptees. American Journal of orthopsychiatry, $\underline{45}(1), 18-26$.

Stein, L. \& Hoopes, J. (1985). Identity formation in the adopted adolescent: The Delaware family study. New York: Child Welfare League of America.

Stone, F. (1972). Adoption and identity. Child Psychiatry and Human Development, $\underline{2}(3), 120-128$.

Tan, A., Kendis, R., Fine, J. \& Porac, J. (1977). A short measure of Eriksonian ego identity. Journal of Personality Assessment, 41(3), 279-284.

Tec, L. \& Gordon, S. (1967). The adopted child's adaptation to adolescence. American Journal of Orthopsychiatry, $\underline{37}(2), 402$.

Terry, A. (1986). Self-esteem and self-concept handouts, COUN 506A--stress and Self-Esteem, Portland State University, Portland, OR. 
Triseliotis, J. (1975). In Sorosky, Baran, \& Pannor; Identity conflicts in adoptees. American Journal of Orthopsychiatry, 45(1), 18-26.

willerman, L. (1979). The psychology of individual and group differences. San Francisco: Freeman \& Co. 
APPENDIX A

SOCIAL ATOM 
SOCIAL ATOM

Directions :

On a blank sheet of paper, write down the names of people (limit of ten) who are or have been most socially or emotionally significant in your life. For each person, write down the person's First Name/Age/Relationship to you and letter the names with "a," "b," "c," etc. as you go. Using a scale from 0 (lowest) to 5 (highest) place the number next to each name that best designates how influential that person is in your life. (Influential = what ability they have to change how you think and feel.) Now, in front of you is another piece of paper that represents the universe. The dot in the center of the page represents you. Using a dot to represent each person you have already listed, place each in relation to you in your Social Atom using the following guidelines:

1. The closer you feel to the individual, place the dot closer to you. (Please letter your dots to correspond to the letter next to each name you designated on your first page.)

2. If the person is deceased, please use an $X$ rather than a dot.

3. For Adopted Ss only: Ask after the task has been completed: Have you placed your biological parents in your Social Atom? If not, would you include them and where? 
SOCIAL ATOM SCORING

1. Total number of persons in the Social Atom.

2. Number of "category" types (e.g., mother; father; same sex peers; opposite sex peers; relatives--siblings, grandparents, extended family; and nonfamily adults.

3. Influence score for mother.

4. Influence score for father.

5. Total influence score for parents.

6. Total influence score for same sex peers.

7. Total influence score for opposite sex peers.

8. Total number of same sex peers.

9. Total number of opposite six peers.

10. Category containing the single highest influence score (parent only; peer only; parent and peer; other category or combination).

11. Category of those members of the Social Atom falling closest to the center dot (self), defined by the two closest dots to the self (parent only; peer only; parent and peer; other category or combination).

12. New category added for this research: Family score total and number in the category. Family is defined as parents, step-parents, and all others in the category "relatives." 
APPENDIX B

SEMI-STRUCTURED INTERVIEW 


\section{SEMI-STRUCTURED INTERVIEW}

\section{DEMOGRAPHIC FACE SHEET}

Name:

\section{Address:}

Phone:

Code \#:

Method of Placement:

Race/Ethnicity:

Living with Parent(s)?

Ever Belonged to Adoptive Family Support Group?

Others in Household:

Name Relation to Participant
Where Seen:

Date:

Age:

Grade:

Age at Placement:

Parents' Same?

Parents Divorced?

D.O.B. Sex Adopted? 
SEMI-STRUCTURED INTERVIEW QUESTIONS

(Questions marked with an asterisk were changed for this study. Changes follow the original.)

PART I: Questions specifically for Adopted Ss:

1. At what age were you adopted?

2. How old were you when you were first told of your adoptive status?

3. At what age would you have liked to be told?
a. earlier (3)
b. same age (4)
c. later (2)
d. not at all (1)

*4. Were you ever told why you were placed for adoption? Why do you think you were placed?

5. What was your reaction to being told that you were adopted?

a. very upset (1)

b. mildly depressed (2)

c. little or no negative reaction (3)

6. How sure are you that your parents told you all they know?
a. very doubtful (1)
b. unsure (2)
c. definitely convinced (3) 
7. How satisfied were you with the information given to you about your adoption?
a. dissatisfied
(1)
b. ambivalent (2)
c. satisfied

8. Could you tell me how comfortable you think your parents feel about your adoption?
a. very comfortable/no perceived anxiety
b. neutral (2)
c. uncomfortable/considerable anxiety perceived

9. How openly discussed is the fact that you're adopted?
a. quite openly discussed
b. occasionally discussed
(2)
c. never or very rarely mentioned

10. When adoption is discussed now, how would you characterize the manner in which it is discussed? (how often and how comfortably?)
a. frequently/little or no discomfort (6)
b. frequently/lots of discomfort (2)
c. occasionally/little or no discomfort (5)
d. occasionally/lots of discomfort (3)
e. seldom or never/little or no discomfort (4)
f. seldom or never/lots of discomfort (1)

11. How has the communication style about adoption been over the years?

(same choices as \#10) 
*12. In your opinion, is your adoption discussed:

a. frequently enough (no change in style advocated) 3

b. with more or less appropriate frequency

c. with inappropriate frequency, i.e. with (1)

not enough discussion or

too much discussion

*13. Some kids have wondered about their biological parents; others have not; others have actually tried to obtain information about them. Which would you say best characterizes you?

a. actively seeking information with the intention of meeting biological parents

b. actively seeking information but with no intention of meeting biological parents

c. wondered a lot about biological parents but never have tried to obtain information

d. never wondered

14. If you have attempted or might attempt to seek information, would you be interested in:

a. specific identifying information (name, address, etc.)

b. general information (general characteristics with no specific identifying information--nationality, physical characteristics, health history, etc.) 
*15. Could you describe to me what you think your biological parents would be like?

16. How similar in appearance are you to your adoptive parents/family?
a. very similar physical characteristics (3)
b. somewhat similar (2)
c. very different in appearance

*17. How do you think things would be for you if you were not adopted?
a. considerably better
b. slightly better (2)
c. no different than it is now (3)
d. slightly worse (4)
e. considerably more problematical

*18. What in your estimation would be an appropriate time to tell a youngster about his/her adoption and why?
a. before 6 years
b. 6-12 years
c. teenage years
d. early adult years
e. never

*19. Would you consider adopting a child? Why? 
PART II. The following questions have to do with your family: all Ss.

20. How do you get along with you mother at present? How would you describe you relationship with her?
a. compatible
b. neutral (2)
c. incompatible

21. How do you get along with your father at present? What is your relationship with him like?
a. compatible
b. neutral (2)
c. incompatible

22. How would you describe your relationship with your brothers and sisters at present?
a. compatible
b. neutral (2)
c. incompatible

If different with specific siblings, specify:

23. How comfortable do you feel within your family?
a. definite sense of belonging described (3)
b. variable (2)
c. estranged (1) 
24. How would you describe your role or place in the family?
a. comfortably esteemed
b. neutral (2)
c. held in low regard

25. How comfortable are you in having opinions that differ from those of your parents?
a. very comfortable (3)
b. somewhat comfortable (2)
c. rarely comfortable (1)

26. Have your parents been able to accept you as a separate individual with opinions of your own?
a. frequently
b. occasionally
c. rarely

27. Are you able to disagree with your parents openly and maintain a different opinion without feeling a loss of support?
a. frequently
b. occasionally
c. rarely

28. How able are you to negotiate differences of opinions with your mother? (Stepmother, where applicable)
a. most often able (3)
b. $50-50$ (2)
c. rarely 
29. How able are you to negotiate differences of opinion with your father? (Stepfather, where applicable)
a. most often able (3)
b. $50-50(2)$
c. rarely (1)

30. How would you describe the way your family communicates?
a. generally smooth: open and easy most of the time (3)

b. occasional breakdowns in communication but generally open (2)

c. communications poor with frequent breakdowns (1)

31. What do you think your parents would say about how you are doing in general?
a. very well
b. fair (2)
c. poorly (1)

For nonadopted Ss only:

*32. How do you think things would be for you if you were adopted?
a. Considerably better
b. slightly better
c. No different than it is now
d. Slightly worse
e. Considerably more problematical 
For Adopted Ss only

33. Does being adopted affect how things go for you within the family?
a. no effect at all (3)
b. some effect (2)
c. significant negative effect (1)

Sum: Family Factor

PART III. The following questions have to do with your peer group:

*34. Do you tend to have friends that you can depend on? What kinds of relationships are they?

35. How would you characterize the relationships you have?
a. Warm, close, dependable relationships
b. mixed (2)
c. distant or undependable relationships

36. How satisfied are you with the quality of your friendships?
a. very satisfied
b. somewhat satisfied
c. dissatisfied

(2) 
37. How satisfied are you with the number of friendships you have?
a. very satisfied
b. somewhat satisfied
c. dissatisfied

38. When you think about how other kids are doing, how would you say you are doing?
a. better than most or equally as well (3)
b. slightly less well (2)
c. poorly

39. What would other kids would say how you're doing?
a. very well
b. fair (2)
c. poorly

40. How open do you feel you can be with your friends about your real thoughts and feelings?
a. very open (3)
b. somewhat open (2)
c. not at all open (1)

*41. Are you dating yet? How interested are you in going out with boys/girls? 
42. How comfortable do you feel around members of the opposite sex?
a. very comfortable (3)
b. somewhat comfortable (2)
c. uncomfortable (1)

43. How attractive do you feel you are to members of the opposite sex?
a. attractive (3)
b. average (2)
c. unattractive

44. How open do you feel you can be with your friends about your adoption?
a. very open (3)
b. selectively open (2)
c. closed (1)

45. What kind of effect does being adopted have upon your feelings of acceptance by peers?
a. no effect at all (3)
b. some effect
c. significant negative effect (1)

46. What kind of effect has your adoption had upon your ability to date or feel comfortable with opposite sex peers?
a. no effect at all (3)
b. some effect (2)
c. significant negative effect (1) 
Sum: Peer Factor

PART IV. The following questions have to do with school:

47. How would you say you are doing in school? That is, what kind of a student would you say you are?
a. above average (3)
b. average (2)
c. below average (1)

48. What would your teachers say about how you are doing?
a. above average (3)
b. average (2)
c. below average (1)

49. What would your parents say about how you are doing in school?
a. very well
b. fair (2)
c. poorly

50. Does your performance in your subjects provide you with any good feelings?
a. rarely/never (1)
b. occasionally (2)
c. frequently (3)
For adopted Ss only:

*51. Do your teachers know that you're adopted? 
52. If so, does this knowledge have any effect upon their interaction with you?
a. no effect (3)
b. some effect (2)
c. significant negative effect (1)

53. What kind of effect does being adopted have upon your academic functioning?
a. no effect (3)
b. some effect (2)
c. significant negative effect (1)

Sum: School Factor

PART V. The following questions relate to you feelings about yourself.

54. How comfortable do you generally feel with yourself?
a. comfortable most of the time (3)
b. comfortable some of the time (2)
c. rarely comfortable (1)

*55. Relative to others, how attractive do you feel physically?
a. quite attractive (3)
b. somewhat attractive (2)
c. not attractive at all (1) 
*56. Relative to others, how attractive a personality do you think you have?
a. quite attractive (3)
b. somewhat attractive
(2)
c. not attractive at all

*57. What types of characteristics, in your opinion, make you seem attractive to others?

*58. If you changed some aspects of yourself for the better, how much change would there have to be?
a. considerable change (1)
b. some change (2)
c. little change (3)

*59. What kind of change would you desire?

*60. How close are you to becoming that person you most want to be?
a. very close (3)
b. moderately close (2)
c. far away (1)

61. What kind of opinion do you hold of yourself?
a. poor opinion (1)
b. so-so opinion of yourself (2)
c. good opinion of yourself (3) 
62. Has being adopted had any effect upon your opinion of yourself?

a. no effect at all (3)

b. some effect (2)]

c. considerable negative effect (1)

Sum: Self-Esteem Factor 
Substitutions for this study:

4. Were you ever told why you were placed for adoption?
a. yes (2)
b. no (1)

12. In your opinion, is your adoption discussed:
a. frequently enough (no change desired)
b. not often enough (2)
c. too often (1)

13. Some kids have wondered about their biological parents; others have not; others have actually tried to obtain information about them. Which would you say best characterizes you?

a. actively seeking information with the intention of meeting birthparents

b. actively seeking information but with no intention of meeting birthparents

c. wondered a lot about birthparents but never have tried to obtain information

d. never wondered/already have all the information needed

e. already have met one or both

15. Do you know other families with adopted kids?
a. yes (2)
b. no (1)

17. How similar in personality are you to your adoptive parents/family? (same choices as \#16) 
18. How do you think things would be for you if you were not adopted?

a. considerably better (1)

b. slightly better (2)

c. no different than it is now (3)

d. slightly worse (4)

e. considerably more problematical (5)

19. Omitted

32. Omitted

34. Do you tend to have friends that you can depend on?
a. yes (2)
b. no (1)

41. How interested are you in dating?
a. very interested (3)
b. somewhat interested
c. not very interested

51. Do your teachers know that you're adopted?
a. most (3)
b. some (2)
c. none (1)

55. Has being adopted had any effect upon your opinion of yourself?
a. no effect at all (3)
b. some effect (2) positive or negative?
c. considerable negative effect (1) 
56. Does knowing other adopted kids affect the way you feel about being adopted?
a. yes, positively
b. no (2)
c. yes, negatively

57. Do you know any adults who were adopted?
a. yes (2)
b. no (1)

58. Does this affect the way you feel about being adopted?
a. Yes, positively
b. no (2)
c. yes, negatively 
APPENDIX C

FREQUENCY DISTRIBUTION: RESPONSES

TO INTERVIEW QUESTIONS 
FREQUENCY DISTRIBUTION: RESPONSES

TO INTERVIEW QUESTIONS

Question \# Responses

$\begin{array}{lll}1 & 2 & 3\end{array}$

1: NS (Not Scored)

2: NS

3: NS

4: NS

5:

$\begin{array}{lll}0 & 1 & 17\end{array}$

6:

$\begin{array}{lll}1 & 5 & 12\end{array}$

7:

$\begin{array}{lll}5 & 7 & 6\end{array}$

8:

1116

9: NS

10: NS

11: NS

12:

$\begin{array}{lll}0 & 3 & 15\end{array}$

13: NS

14: NS

15:

216

16:

1062

17 :

6102

18: NS

19: Omitted

Part II. 


\begin{tabular}{|c|c|c|c|}
\hline $20:$ & & 3 & 7 \\
\hline $21:$ & & 2 & 4 \\
\hline $22:$ & & 0 & 11 \\
\hline 23: & & 1 & 7 \\
\hline 24: & & 1 & 6 \\
\hline 25: & & 1 & 4 \\
\hline 26: & & 3 & 8 \\
\hline 27: & & 2 & 7 \\
\hline 28: & & 3 & 10 \\
\hline 29: & & 3 & 9 \\
\hline $30:$ & & 5 & 9 \\
\hline 31: & & 1 & 7 \\
\hline $32:$ & Omitted & & \\
\hline 33: & & 0 & 5 \\
\hline
\end{tabular}

Part III.

34: NS

35:

$\begin{array}{lll}0 & 6 & 12\end{array}$

$36:$

$14 \quad 13$

$37:$

$\begin{array}{lll}2 & 7 & 9\end{array}$

38 :

1413

39 :

$\begin{array}{lll}0 & 5\end{array}$

$40:$

2106

41: NS

42:

$\begin{array}{lll}0 & 6\end{array}$

43:

$\begin{array}{lll}3 & 13 & 2\end{array}$




$\begin{array}{llll}44: & 1 & 6 & 11 \\ 45: & 0 & 3 & 15 \\ 46: & 1 & 1 & 16\end{array}$

Part IV

\begin{tabular}{|c|c|c|c|c|}
\hline 47: & & 1 & 11 & 6 \\
\hline 48: & & 1 & 10 & 7 \\
\hline 49: & & 1 & 10 & 7 \\
\hline 50: & & 3 & 9 & 6 \\
\hline 51: & NS & & & \\
\hline $52:$ & & 0 & 2 & 16 \\
\hline $53:$ & & 1 & 1 & 16 \\
\hline
\end{tabular}

Part V.

$\begin{array}{llll}54: & 1 & 6 & 11 \\ 55: & 1 & 7 & 10 \\ 56: & 0 & 15 & 3 \\ 57: & 10 & 8 & \\ 58: & 0 & 17 & 1\end{array}$


APPENDIX D

PARENTAL INFORMED CONSENT 
PARENTAL INFORMED CONSENT

I, hereby

permit my son/daughter

to participate in the research project conducted by Judith K. Bentley.

I understand that the study involves an interview and two pencil and paper tests which will take about an hour to complete.

I understand that participating in this study may bring up questions in his/her mind related to adoption issues and that we may want to talk to someone about them. We will be able to participate in a group that will discuss these questions within a few weeks after my son or daughter participates in the study. At this meeting, information will be provided advising me and ny family of adoptionsensitive community resources. While we may not receive any direct benefit from participation in this study, our participation may help to increase knowledge which may benefit others in the future.

It has been explained that the purpose of this study is to learn about thoughts and feelings on topics of importance to adopted teenagers. Mrs. Bentley has offered to answer any questions I may have about the study and what is expected of my son/daughter in the study. I have been assured that all information s/he gives will be used only for research purposes, that his/her identity will not be disclosed in any discussion of the study's results, and that all participants in this study will remain anonymous in any written reports of the study.

I understand that my son/daughter is free to withdraw from participation in this study at any time.

I have read and understand the foregoing information.

Date Signature

(If you experience problems that are the result of your participation in this study, please contact the secretary of the Human Subject Research Review Committee, Office of Grants and Contracts, 303 Cramer Hall, Portland state University, P. O. Box 751, Portland, OR 97207-0751. Or call us at 725-3417.) 
INFORMED CONSENT

I, , hereby

agree to participate in the research project conducted by Judith K. Bentley.

I understand that the study involves an interview and two pencil and paper tasks which will take about an hour to complete.

I understand that participating in this study may bring up questions in my mind or increase my sensitivity to being an adopted child and that I may want to talk to someone who will understand my anxieties. I will be able to participate in a group that will discuss these questions within a few weeks after my participation in the study. At this meeting, information will be provided advising me and my family of adoption-sensitive community resources. While I may not receive any direct benefit from participation in this study, my participation may help to increase knowledge which may benefit others in the future.

It has been explained that the purpose of this study is to learn about thoughts and feelings on topics of importance to teenagers, especially adopted teenagers. Mrs. Bentley has offered to answer any questions I may have about the study and what is expected of me in the study. I have been assured that all information I give will be used only for research purposes, that my identity will not be disclosed in any discussion of the study's results, and that all participants in this study will remain anonymous in any written reports of the study.

I understand that I am free to withdraw from participation in this study at any time.

I have read and understand the forgoing information.

Date Signature

(If you experience problems that are the result of your participation in this study, please contact the secretary of the Human Subject Research Review Committee, Office of Grants and Contracts, 303 Cramer Hall, Portland state University, P. O. Box 751, Portland, OR 97207-0751. Or call us at 725-3417.) 